\title{
Competing with Privacy
}

\section{Citation}

Casadesus-Masanell, Ramon, and Andres Hervas-Drane. "Competing with Privacy." Management Science (forthcoming).

\section{Published Version}

doi:10.2139/ssrn.2273006

\section{Permanent link}

http://nrs.harvard.edu/urn-3:HUL.InstRepos:13135313

\section{Terms of Use}

This article was downloaded from Harvard University's DASH repository, and is made available under the terms and conditions applicable to Open Access Policy Articles, as set forth at http:// nrs.harvard.edu/urn-3:HUL.InstRepos:dash.current.terms-of-use\#OAP

\section{Share Your Story}

The Harvard community has made this article openly available.

Please share how this access benefits you. Submit a story.

Accessibility 


\title{
Competing with Privacy*
}

\section{Ramon Casadesus-Masanell ${ }^{\dagger} \quad$ Andres Hervas-Drane ${ }^{\ddagger}$}

October 21, 2013

\begin{abstract}
We analyze the implications of consumer privacy for competition in the marketplace. We consider a market where firms set prices and disclosure levels for consumer information and consumers observe both before deciding which firm to patronize and how much information to provide it with. The provision and disclosure of information presents tradeoffs for all market participants. Consumers benefit from providing information to the firm, as this increases the utility they derive from the service, but they incur disutility from information disclosure. This, in turn, benefits the firm providing an additional source of revenue, but reduces consumer demand for the service. We characterize equilibrium information provision, disclosure levels, and prices, and show that competition with privacy has several effects on the marketplace. First, competition drives the provision of services with a low level of disclosure. Second, competition ensures that services with a high level of disclosure subsidize consumers. Third, firms maximize profits at the extensive rather than the intensive margin, outperforming competitors by attracting a larger customer base. And fourth, higher competition intensity need not improve consumer privacy when consumers exhibit low willingness to pay. Our findings are particularly relevant to the business models of Internet firms and contribute to inform the regulatory debate on consumer privacy.
\end{abstract}

Keywords: Information Acquisition, Information Disclosure, Online Privacy, Privacy Regulation

JEL codes: D83, L15, L4, M21

${ }^{*}$ We thank the journal's editors and two anonymous referees for suggestions that helped to improve this paper substantially. We also thank Do Yoon Kim for research assistance, Larbi Alaoui, Andrei Hagiu, and Martin Peitz for helpful comments and suggestions, as well as participants at UPF's internal micro seminar and the ZEW economics of ICT conference. The authors are grateful for financial support from the Spanish Ministry of Economy and Competitiveness grant ECO2011-28965, the IESE Public-Private Sector Research Center, and the HBS Division of Research.

${ }^{\dagger}$ Harvard Business School

${ }^{\ddagger}$ Universitat Pompeu Fabra (andres.hervas@upf.edu) 


\section{Introduction}

Digitalization has dramatically lowered the costs of storing and processing large stocks of consumer information, enabling new forms of advertisement targeting, personalization tools, and price discrimination schemes. Personal consumer information has therefore become a valuable asset in the marketplace and an important element of firm strategy. Nowhere is this trend more visible than in online services, where firms are aggressively capturing large stocks of consumer information. Usage of these information-intensive services by consumers implies provision of personal information, and firms exploit such information to generate new sources of revenue. These tradeoffs are defining business models and the role of privacy in online marketplaces.

Prominent examples of these trends can be identified among major Internet players. Google provides consumers with services to search the web, manage their email correspondence (gMail), contacts (Google + ), calendar events (Google Calendar), and documents (Google Docs). Consumers provide personal information to use these services, informing Google about their location, interests, and social connections when performing searches, communicating with others, and managing their documents, and derive a direct benefit from the services in doing so. Google in turn derives revenues from disclosing this information by profiling consumers and charging advertisers to target them. A larger stock of consumer information increases the effectiveness of the targeting and allows Google to derive higher disclosure revenues, although advertising reduces the benefits consumers derive from the services. Google's business model is readily understood by consumers: free services in exchange for ads. ${ }^{1}$

Other major Internet players such as Microsoft and Amazon compete with different approaches. Microsoft has recently introduced Office 365, an online service which competes with Google's by allowing consumers to edit documents, manage email, contacts, and calendar events. In contrast with Google, however, Microsoft charges consumers for the service and does not disclose their information for advertising purposes. Microsoft's recent Scroogled! campaign emphasized the difference in the following terms: "Google goes through every gMail that's sent or received, looking for keywords so they can target gMail users with paid ads. And there's no way to opt out of this invasion of your privacy. Outlook.com is different — we don't go through your email to sell ads."

Amazon plays an important role in online search by indexing a large number of products and allowing third-party sellers to supply them through its websites, competing with Google as a search gateway in the retail arena. Amazon also exploits consumer information to profile users based on their search interests and past purchases, and derives revenues by disclosing this information to sellers. Furthermore, through its Special Offers program, Amazon has started to subsidize

\footnotetext{
${ }^{1}$ We use the term disclosure to refer to the exploitation of consumer information for revenue-generating purposes, even though some forms of exploitation may not imply information sharing with third-parties. For example, spot markets for online advertising may not allow advertisers to observe the identity of target consumers. Nonetheless, we expect the outcome to approximate that of information sharing because the firm exploiting the information will account for the objective function of advertisers in order to maximize revenues.
} 
consumers willing to accept advertising on their mobile devices. Consumers currently benefit from $\$ 15$ and $\$ 20$ discounts when purchasing Kindle tablets and e-readers, respectively, if willing to accept targeted advertisements from Amazon and third-party sellers displayed on the device. This subsidy renders the basic Kindle e-reader one of the cheapest devices of its kind.

These examples illustrate the choices consumers face when providing their personal information to online services and the revenue streams firms can tap into by disclosing it. The question is now, how does this affect competition? Should firms exploit all available revenue sources, prices and disclosure, or focus on one? If so, which is more profitable and what does it depend on? In this paper we present a model to analyze the strategic interactions generated by consumer information provision and firm disclosure and how they affect competition in the marketplace. To the best of our knowledge, we contribute the first analysis that explains how the provision and disclosure of consumer information shapes the competitive interaction of firms.

We build on a standard vertical differentiation framework to capture the informational dimension of the problem, and do so by adopting a reduced-form specification for service quality which captures the tradeoffs outlined above. Firms provide a homogeneous service to consumers and compete on prices and information disclosure. On the demand side, consumers are the gatekeepers of their personal information, and they observe the level of disclosure firms engage in as well as their price before deciding which service to patronize (if any) and how much personal information to provide it with. The perceived quality of the firm's service for each consumer increases with information provision and decreases with the firm's level of disclosure. On the supply side, there are two revenue sources available to firms: sales revenues originating from the prices charged to consumers, and disclosure revenues which depend on their level of disclosure and stock of consumer information. Firms may choose to exploit both, to forego sales revenues by subsidizing consumers, or to forego disclosure revenues by not engaging in disclosure.

Our analysis provides insight on how firms compete for consumer information. We show that firms can exploit consumer heterogeneity by differentiating in their levels of information disclosure, and can profit from doing so even though this sacrifices disclosure revenues. Differentiation is reflected on both the level of disclosure firms engage in as well as on the revenue source they choose to exploit. A firm engaging in a high level of disclosure (low-quality service) chooses to subsidize consumers, and a firm engaging in a low level of disclosure (high-quality service) charges positive prices. Such an outcome is a direct consequence of competition, as we show that a monopolist never chooses to subsidize consumers. Moreover, the presence of disclosure revenues can drive the high-disclosure (low-quality) firm to derive higher profits in the marketplace, contrary to what would be predicted by a standard vertical differentiation framework.

Our analysis also provides insight on the effect of competition on consumer privacy by explaining the aggregate stock of consumer information disclosed by firms. We find that the stock of consumer information disclosed in the marketplace is generally lower under competition than under monopoly. Thus consumers derive higher surplus and benefit from competition, as should 
be expected. But perhaps counterintuitively, higher intensity of competition between firms (which can be captured in our analysis by the heterogeneity of the consumer population) can result in an increase the stock of information disclosed, reducing consumer privacy. Consumers still benefit from competition, but do so through prices (or subsidies) rather than through reductions in the disclosure of their information. Moreover, we also find that the high-disclosure firm can contribute the most to consumer surplus. From a policy perspective, this implies that high levels of disclosure can be expected in a competitive marketplace and need not reduce consumer welfare when compensated by subsidization.

The model we use to derive our results is internally complex but tractable, and provides for clean qualitative predictions in equilibrium. We fully endogenize all the information decisions of market participants, and the only exogenous parameters in our analysis are those that define the distribution of consumer valuations for the service. To obtain the results, several simplifications are needed. We do not model the interactions arising in the secondary market for consumer information disclosure. Instead, we assume firms operate as price-takers, for example by participating in a competitive advertising market. We restrict our analysis to covered market equilibria where all consumers choose to sign up for one of the services, and consider only the case where consumer valuations are uniformly distributed and marginal costs are zero. Our analysis is best suited to online services operating with large user bases and negligible marginal costs.

Our model provides a benchmark for consumer privacy in the context of informed and rational consumers. We assume consumers are aware of the disclosure practices of firms and internalize their impact in their decisions and usage of services. Consumers have access to a growing set of resources to learn about these practices, and privacy regulations increasingly require firms to inform prospective customers about their disclosure activities. ${ }^{2}$ Although we recognize that factors such as bounded rationality or cognitive biases can distort consumer decisions regarding the provision of their personal information, we expect consumers to become increasingly familiar with privacy tradeoffs in the marketplace. Such consumers can be interpreted as privacy pragmatists according to survey classifications of privacy attitudes: they are concerned about privacy but are willing to trade it off if an evaluation of the benefits and risks pays off. A growing majority of US consumers have been reported to pertain to this category. ${ }^{3}$

In the next section, we position our paper in the context of the recent managerial and economics literature relating to online privacy. Section 2 introduces the building blocks of our model and

\footnotetext{
${ }^{2}$ News outlets, consumer advocacy groups, and industry initiatives provide consumers with avenues to learn about the privacy practices of online services. For example, The Wall Street Journal has recently published indepth reports about online privacy explaining common disclosure schemes, the Electronic Frontier Foundation tracks and reports industry developments and best-practices, and Privacy Score provides consumers with updated scoreboards for popular online services. Privacy regulations are also playing a role in fostering consumer awareness. For instance, EU Directive 2009/136/EC requires websites that employ activity tracking tools such as cookies to explicitly disclose their existence to consumers in a comprehensive and user-friendly manner.

${ }^{3}$ See Alan Westin's report 'How online users feel about behavioral marketing and how adoption of privacy and security policies could affect their feelings,' Privacy Consulting Group, March 2008.
} 
the timing of the game. We characterize the monopoly solution in Section 3. This serves as a benchmark to evaluate the implications of competition. We proceed to solve the case of duopoly in Section 4, explain the drivers of differentiation and provide a qualitative comparison of the duopoly and monopoly outcomes. In Section 5 we discuss the managerial and policy implications of our results by examining firm performance and consumer privacy in equilibrium, and also review the main empirical implications of our model. Section 6 concludes.

\section{$1.1 \quad$ Literature}

Privacy is a multidisciplinary concept which has been studied across several fields including economics, law, sociology, and political science. Our work relates to the economic dimension of privacy, understood as the control over access to information by economic agents and its associated tradeoffs. Posner (1981) and Stigler (1980) famously argued that privacy can lead to allocation inefficiencies, and is therefore undesirable in the absence of externalities or explicit preferences for privacy. This view has been challenged more recently. Hermalin and Katz (2006) analyze the implications of different privacy regimes and their impact on allocative efficiency in the absence of such externalities and preferences, and find that privacy can be socially desirable in some cases. Calzolari and Pavan (2006) evaluate information disclosure between two principals sequentially contracting with a common agent who strategically decides whether to report her true type, and show that the effect of privacy on welfare is ambiguous. Hui and Png (2006) provide a survey on the economics of privacy and argue that externalities generally play an important role in the collection and exploitation of consumer information.

Our approach is motivated by the most prevalent forms of exploitation of consumer information in online services, such as advertising. These forms of exploitation have a negative impact on consumers in the form of attention costs or search bias (or do so beyond some overload threshold). In addition, consumers generally exhibit an explicit preference for privacy over their communication channels. Noam $(1995 \mathrm{a}, 1995 \mathrm{~b})$ provides a prescient account of the privacy implications of advances in electronic telecommunications, and argues that a competitive marketplace can contribute solutions to consumer demands for privacy. Spulber (2009) reviews the evolving market structure of online search and advertising services, and argues that competition in this market can discipline the disclosure policies of search firms and increase the share of the surplus appropriated by consumers. Our work formalizes these arguments and explains the precise impact of competition in this market. We show that gains in consumer surplus associated with higher intensity of competition need not result in privacy improvements when information disclosure is profitable for firms.

Our model relates to the growing literature on two-sided markets pioneered by Rochet and Tirole (2003) and Caillaud and Jullien (2003), as well as later contributions such as Armstrong (2006). Firms in our model can be interpreted to intermediate a two-sided market where con- 
sumers provide personal information on one side and advertisers purchase the information which is disclosed on the other side. Most applications in the literature consider settings where each side of the market benefits from participation on the other side, implying that positive externalities are present between both sides. In our setting, similarly to Casadesus-Masanell and Zhu (2010), consumers benefit from the services provided by the intermediary firms but derive disutility from disclosure, implying that the disclosure side generates negative externalities on the consumer side. Thus our model also addresses the question of when it is optimal for firms to adopt a one-sided business model and exclude the side that generates negative externalities.

Our model does not explicitly address the rationale for intermediation in the marketplace, though we note that such intermediation is consistent with the presence of negative externalities. Sandholm (2005) provides a general framework to show that pricing schemes can improve efficiency in the presence of negative externalities. For the case of advertising, intermediation can improve targeting precision and reduce the attention costs imposed on consumers, thereby increasing allocative efficiency as analyzed by Van Zandt (2004). Our model provides a rich characterization of the consumer side of the market but in turn simplifies the disclosure side, where prices are assumed to be fixed and exogenous and therefore unaffected by the actions of firms. The pricing of consumer information is a complex problem and is beyond the scope of our analysis. Baccara (2007) presents a general equilibrium model that explains the price of information in the R\&D context, where contractors may disclose the information of their customers, and finds that higher concentration in the market for information (fewer contractors with higher market power) raises the price of information. In our model, such an effect would reduce the disclosure revenues firms derive when simultaneously engaging in disclosure, reinforcing the incentives for differentiation. ${ }^{4}$

A recent strand of the theoretical literature has examined the implications of consumer privacy with regard to anonymity and price discrimination. If firms can identify returning consumers, they may infer their willingness to pay and set prices accordingly. Villas-Boas (2004) considers the case of a monopolist facing both new and returning consumers, and shows that optimal pricing can exhibit price cycles over time. Taylor (2004) considers the case of two sequential sellers and examines how information disclosure between sellers affects their pricing strategies. Acquisti and Varian (2005) examine the case where sophisticated consumers can use anonymizing tools and firms can offer improved service to those that choose to remain identifiable. Conitzer, Taylor and Wagman (2012) analyze the impact of the cost of anonymity for consumers facing a monopolist, and show that increasing the cost of anonymity can benefit consumers.

Our focus differs from the above contributions in that we consider the effect of consumer

\footnotetext{
${ }^{4}$ The price commanded by the personal information of consumers will also depend on its broader availability. Note that consumers single-home in our model, so firms become gatekeepers of the information they accumulate through their services. Reports from the data brokerage industry suggest that consumer information in abundant supply such as names, addresses, and emails, as well as demographics including age, race, and occupation, command a low price in the marketplace. Information on sensitive topics such as health related interests and gambling propensity, or time-sensitive events such as marriage, pregnancy, or divorce, are in limited supply and command higher prices. See for instance 'Everything we know about what data brokers know about you', ProPublica, March 72013.
} 
information provision on the quality of services rather than on prices. Our approach relates to that of Akçura and Srinivasan (2005), who first examined the tradeoff faced by the monopolist deriving both sales revenues and disclosure revenues. They analyze the case where the monopolist decides the supply of information required of consumers in order for them to participate in the service. Our approach differs in that we examine the case where consumers unilaterally decide how much information to provide and we also analyze competition. Because consumers derive positive utility from information provision in our model, our approach is better suited to applications where consumers directly benefit from providing information (e.g., search engines, cloud storage) and Akçura and Srinivasan's model is better suited to applications where consumer information mainly benefits the firm (e.g., airline bookings, retail banking). We further relate our findings to those of Akçura and Srinivasan in our monopoly analysis in Section 3.

In recent years, several papers have examined consumer attitudes toward online privacy. Chellappa and Sin (2005) present a survey to evaluate the tradeoff consumers face when providing personal information to online services. They measure consumer valuations for the personalization benefits as well as consumer concerns regarding alternative uses of their information by the firm. They find that consumers' positive valuation for personalization exceeds their negative concern for privacy. Tsai et al. (2011) report an online shopping experiment based on a search engine where results are annotated with privacy ratings based on sellers' privacy policies. They find that subjects are willing to pay a premium for privacy when such information is salient. Tucker (2011) analyzes the effectiveness of a personalized advertising campaign in a social network, and finds that it is positively affected by consumers' perceived control over the use of their personal information. The findings reported in these papers suggest that consumers account for privacy considerations when deciding which firms to patronize and how much personal information to provide.

Other empirical contributions have considered the supply side of the market. Preibusch and Bonneau (2013) analyze the degree of differentiation in the data collection policies of major Internet sites according to traffic rank in several service categories. They find a significant degree of differentiation in search engines and social networking, categories that meet the characteristics of those considered here. They also find that services operating under less competition tend to request consumers to supply more personal information. Goldfarb and Tucker (2010) evaluate the impact of privacy regulations in Europe on the effectiveness of online advertising. These regulations restrict the information that can be collected and processed from consumers for the purpose of targeted advertising, in effect restricting information disclosure by firms. They find that such restrictions significantly reduce advertising effectiveness, and should therefore be expected to reduce the disclosure revenues of firms. 


\section{The model}

Consider a market with two firms and a unit mass of consumers. Firms supply a homogeneous service and compete on two separate dimensions: price and privacy. Each firm sets a price $p_{j}$ and a level of consumer information disclosure $d_{j}$ for its service. Consumers are heterogeneous in their valuation of the service, which is uniformly distributed across the consumer population. The valuation of consumer $i$ is given by $v_{i} \sim U\left[V^{-}, V^{+}\right]$. For tractability, we restrict our analysis to equilibria where the market is covered. A necessary condition that guarantees full market coverage is $0<V^{-}<V^{+}<2$.

Consumers participating in the market and signing up to the service of one of the firms decide how much personal information to provide, and we denote the information provision of consumer $i$ to firm $j$ by $y_{i, j} \cdot{ }^{5}$ The utility derived by consumer $i$ from firm $j$, given price $p_{j}$ and disclosure level $d_{j}$, is given by

$$
u_{i, j}=v_{i} y_{i, j}\left(1-y_{i, j}-d_{j}\right)-p_{j}
$$

where the expression $y_{i, j}\left(1-y_{i, j}-d_{j}\right)$ captures the informational quality of firm $j$ 's service for consumer $i$. The specification implies that informational quality is concave in $y_{i, j}$ and decreasing in $d_{j}$, so consumers stand to benefit from providing information $y_{i, j}$ to the firm but incur disutility from firm disclosure $d_{j}{ }^{6}$ The marginal benefit of information provision is decreasing: the information provided by each consumer is decreasing in its relevance to the service. Both $y_{i, j}$ and $d_{j}$ are endogenous and will be jointly determined in equilibrium. Consumers need to provide some information to derive positive utility from the service and firms may choose to engage or not in disclosure, $y_{i, j} \geq 0$ and $d_{j} \geq 0$. Also note that the first term on the right-hand side of (1) identifies the consumer's willingness to pay for the service. Consumers may sign up for the service of one of the firms or remain out of the market, and so we normalize the outside utility of consumers to zero.

Firm profits originate from two revenue sources, the prices directly charged to consumers and disclosure revenues originating from the exploitation of consumer information. We simplify the latter by adopting a reduced form for disclosure revenues. The profits of firm $j$ when serving consumers $v_{i} \in\left[v_{j}^{-}, v_{j}^{+}\right]$are given by

$$
\pi_{j}=\frac{1}{V^{+}-V^{-}} \int_{v_{j}^{-}}^{v_{j}^{+}} p_{j}+d_{j} y_{i, j} \mathrm{~d} v_{i} .
$$

Our specification implies that disclosure prices are exogenous and are normalized to 1 . Note

\footnotetext{
${ }^{5}$ When usage of the service implies information provision, $y_{i, j}$ can also be interpreted as usage intensity.

${ }^{6}$ We assume for simplicity that consumers always derive disutility from disclosure. If consumers exhibit an acceptance threshold for disclosure, for example if a certain degree of advertising is acceptable, then disclosure in our model can be interpreted as the level of excess advertising that firms engage in.
} 
however that the relative weight of disclosure revenues with respect to the price revenues charged to consumers will depend on consumers' willingness to pay, which in turn depends on the firm's level of disclosure and consumer valuations for the service. The boundaries on $V^{-}$and $V^{+}$ensure that the analysis encompasses cases where feasible disclosure revenues are higher than price revenues and cases where they are lower. We also let firms set negative prices if they choose to subsidize consumers. We assume that firms face zero marginal costs to simplify the analysis, and without loss of generality, assume fixed costs are zero.

The timing of the game is as follows. In the first stage, firms simultaneously set their disclosure level $d_{j}$. In the second stage, firms simultaneously set prices $p_{j}$. In the third stage, having observed disclosures and prices, consumers choose to sign up for the service offered by one of the firms or to stay out of the market. In the fourth stage, consumers patronizing a firm decide how much information $y_{i, j}$ to provide it with.

Firms are committed to the level of disclosure they announce in the first stage and cannot increase it after obtaining consumers' personal information. This modeling assumption reflects the fact that reputational concerns and privacy regulations make it costly for firms to backtrack on their disclosure commitments or to deceive consumers. For example, the Gramm-Leach-Bliley Act requires US financial institutions to provide consumers with a notice and opt-out opportunity before they disclose their information to unaffiliated third-parties, making it costly for firms to increase information disclosure ex-post. Another example is that of US retailer Toysmart.com, which after filing for bankruptcy was blocked by the FTC from selling customer information. The sale was considered deceitful to consumers because the company's privacy policy stated that "when you register with Toysmart.com, you can rest assured that your information will never be shared with a third-party."7

\section{Monopoly benchmark}

We start our analysis by considering the monopoly case, which serves as a benchmark to evaluate the impact of competition in the next section. We proceed to solve the monopolist's optimization program by backwards induction.

Information provision. Consider the problem of consumer $i$ in the fourth stage when deciding how much information to provide firm $j$ with when using its service. The consumer maximizes $u_{i, j}$ in (1) by choosing $y_{i, j}$ given the firm's disclosure level $d_{j}$ and price $p_{j}$, which implies

$$
y_{i, j}=\frac{1-d_{j}}{2}=y_{j}
$$

Optimal information provision is homogeneous across consumers, $y_{i, j}=y_{i^{\prime}, j}$ for all $i$ and $i^{\prime}$, so that

\footnotetext{
${ }^{7}$ See 'FTC Sues Failed Website, Toysmart.com, for Deceptively Offering for Sale Personal Information of Website Visitors,' FTC press release, July 2000.
} 
the firm obtains the same amount of information from each of its users.

Purchasing decisions. We next consider the problem of consumer $i$ in the third stage when deciding to sign up for firm $j$ 's service or stay out of the market. The consumer evaluates the utility derived from the service given by $u_{i, j}$ in (1), anticipating optimal information provision given by (2), and signs up only if $u_{i, j} \geq 0$. We proceed by identifying the valuation of the indifferent consumer $v_{f}$ who is strictly indifferent between signing up or not. Solving for $u_{f, j}=0$ yields

$$
v_{f}=\frac{4 p_{j}}{\left(1-d_{j}\right)^{2}}
$$

Note that $\partial u_{i, j} / \partial v_{i}>0$ given optimal information provision in (2), so consumers with a higher valuation than the indifferent consumer $v_{i}>v_{f}$ will prefer to sign up and those with lower valuation $v_{i}<v_{f}$ will prefer to stay out. Therefore, when $v_{f}>V^{-}$, some consumers do not sign up and the market is uncovered, and when $v_{f} \leq V^{-}$, all consumers sign up and the market is covered. Because the monopolist's demand differs in the covered and uncovered market configurations, both cases need to be considered separately in what follows.

Monopoly pricing. We next analyze the pricing problem of the monopolist in the second stage given disclosure level $d_{m}$. Consider first the case of an uncovered market. Given that consumer information provision in (2) is homogeneous across all consumers signing up for the service, we can write the monopolist's profits as

$$
\pi_{m}^{u}\left(p_{m}, d_{m}\right)=\frac{V^{+}-v_{f}}{V^{+}-V^{-}}\left(p_{m}+d_{m} y_{m}\right)
$$

and solving for the optimal price in an uncovered market, denoted by $p_{m}^{u}$, obtains

$$
p_{m}^{u}=\frac{\left(1-d_{m}\right)\left(V^{+}\left(1-d_{m}\right)-2 d_{m}\right)}{8}
$$

Consider next the case of a covered market. Monopoly profits are then given by

$$
\pi_{m}^{c}\left(p_{m}, d_{m}\right)=p_{m}+d_{m} y_{m}
$$

and the monopolist's optimal price in a covered market, denoted by $p_{m}^{c}$, is given by the highest price that ensures all consumers sign up. In this case, the indifferent consumer $v_{f}$ must coincide with the consumer with the lowest valuation in the population. Equating $v_{f}\left(p_{m}^{c}, d_{m}\right)=V^{-}$yields

$$
p_{m}^{c}=\frac{V^{-}\left(1-d_{m}\right)^{2}}{4}
$$

Monopoly disclosure. Consider the first stage when the monopolist sets disclosure level $d_{m}$. Inspection of $y_{j}$ in $(2)$ reveals that the valid disclosure range of the firm is given by $d_{j} \in[0,1]$, given that negative disclosure or negative information provision are both unfeasible. In an uncovered 
market configuration, plugging optimal price $p_{m}^{u}$ in (5) into profits $\pi_{m}^{u}$ in (4) obtains monopoly profits as a function of disclosure $\pi_{m}^{u}\left(d_{m}\right)$. Maximizing $\pi_{m}^{u}\left(d_{m}\right)$ with respect to $d_{m}$ subject to the constraint $d_{m} \geq 0$ (feasible disclosure range) and $v_{f}\left(p_{m}^{u}, d_{m}\right)>V^{-}$(uncovered market) obtains optimal disclosure in an uncovered market $^{8}$

$$
d_{m}^{u}=0 \quad \text { if } \quad V^{-}<\frac{2+V^{+}}{2} \text { and } \quad V^{+} \geq 2
$$

No uncovered market solution exists outside this parameter range. Therefore, a necessary condition for the monopolist to choose not to cover the market is $V^{+} \geq 2$, which we have ruled out (see Section 2).

Consider next the case of a covered market. Plugging $p_{m}^{c}$ in (7) into $\pi_{m}^{c}$ in (6) obtains profits as a function of disclosure $\pi_{m}^{c}\left(d_{m}\right)$. Recall that optimal price $p_{m}^{c}$ ensures that the market is effectively covered. Maximizing $\pi_{m}^{c}\left(d_{m}\right)$ with respect to $d_{m}$ subject to the constraint $d_{m} \geq 0$ (feasible disclosure range) obtains optimal disclosure in a covered market

$$
d_{m}^{c}= \begin{cases}\frac{1-V^{-}}{2-V^{-}} & \text {if } V^{-}<1 \\ 0 & \text { if } V^{-} \geq 1\end{cases}
$$

The following proposition summarizes the above results.

Proposition 1. The monopolist chooses to cover the market in equilibrium and customers provide information $y_{m}=\left(1-d_{m}\right) / 2$. When $V^{-}<1$, the monopolist sets disclosure level $d_{m}=(1-$ $\left.V^{-}\right) /\left(2-V^{-}\right)$and price $p_{m}=V^{-} / 4\left(2-V^{-}\right)^{2}$. When $V^{-} \geq 1$, the monopolist sets $d_{m}=0$ and $p_{m}=V^{-} / 4$.

The monopolist faces an important tradeoff in determining the price and the level of information disclosure offered to consumers. On the one hand, an increase in price reduces demand for the service, which reduces the user base and the information stock over which the firm can extract disclosure revenues. On the other hand, an increase in the level of disclosure decreases consumers' willingness to pay for the service, thus reducing price revenues. In addition, the monopolist faces an information provision tradeoff when setting the level of disclosure. The provision of information by consumers signing up for service is decreasing in the level of disclosure, and consumers prefer not to provide information to the firm when it engages in maximum disclosure. As a consequence, the monopolist considers only intermediate levels of disclosure, striking a balance between the information stock obtained from consumers and the revenues from disclosing it.

The monopolist always covers the market in equilibrium. If there are consumers with low valuations for the service $\left(V^{-}<1\right)$, it chooses to engage in information disclosure $\left(d_{m}>0\right)$.

\footnotetext{
${ }^{8}$ Note that $\pi_{m}^{u}\left(d_{m}\right)$ does not depend on $d_{m}$ when $V^{+}=2$. In this particular case, the monopolist is indifferent when choosing disclosure level $d_{m}$, so we proceed by assuming that the monopolist chooses $d_{m}=0$ under indifference.
} 

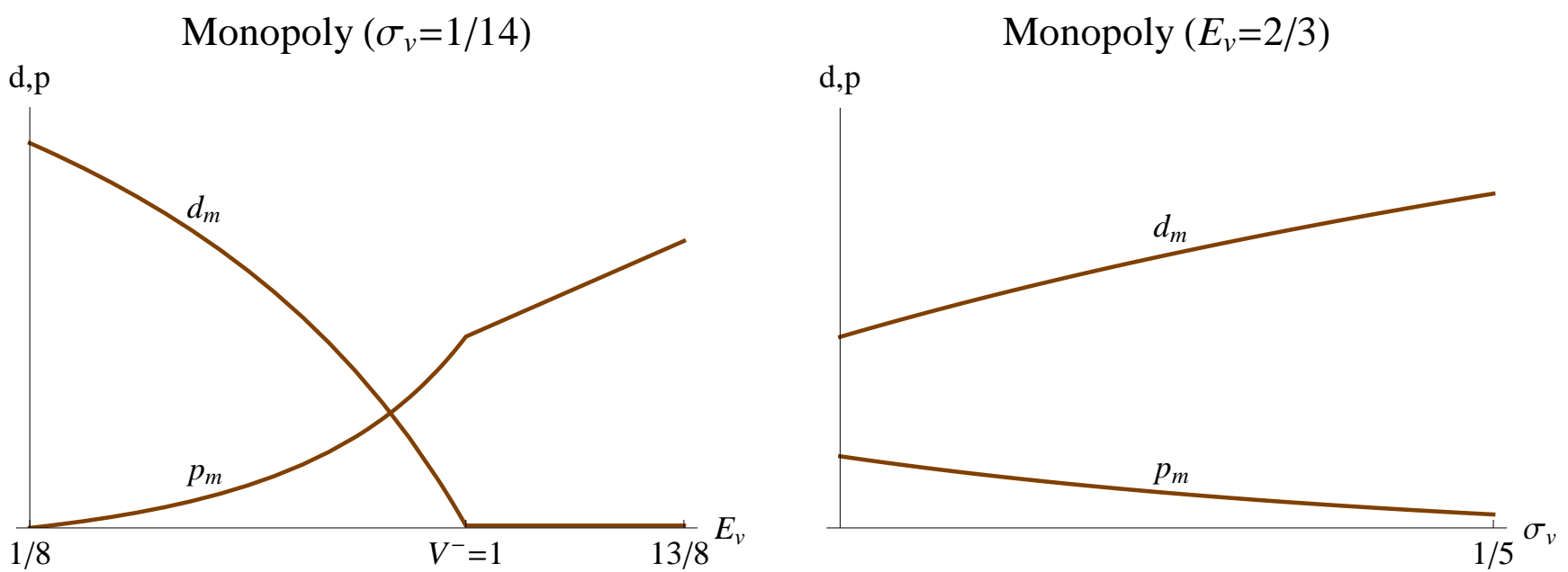

Figure 1: Monopoly disclosure and price as a function of the consumer population's valuation mean (left) and spread (right). The axes origins are located at $(0,0)$ in all plots unless otherwise noted.

Moreover, because $\partial d_{m} / \partial V^{-} \leq 0$, the larger the mass of consumers with low valuations, the higher the level of disclosure. Intuitively, when average willingness to pay for the service is low, the monopolist cannot extract much consumer surplus through price revenues. Thus, revenues from information disclosure are comparatively higher and $d_{m}>0$. When willingness to pay for the service is high, however, price revenues become comparatively more attractive and the monopolist prefers that monetization mode. In fact, when $V^{-} \geq 1$, the monopolist chooses not to disclose information $d_{m}=0$ so that it can charge the largest possible price for the service.

Figure 1 illustrates the impact of changes in the mean and in the spread of the consumer population's distribution of valuations. For the reasons just discussed, an increase in the mean valuation that preserves the spread drives the monopolist to increase price and to reduce disclosure. An increase in the spread that preserves the mean of the distribution implies that consumers become more heterogeneous in their valuations, and this reduces the price revenue that the firm can extract. This drives the monopolist to lower the price in order to ensure that all consumers participate and to increase the level of information disclosure.

Our monopoly analysis is closely related to that of Akçura and Srinivasan (2005), who first analyzed the problem of the monopolist facing a tradeoff between sales revenues and disclosure revenues. In both cases, higher levels of information disclosure in equilibrium command lower prices for consumers. An important difference, however, is that the monopolist may subsidize some consumers in their model. This outcome arises in Akçura and Srinivasan's analysis because they consider the case where the monopolist can decide the information provision required of each consumer. In our model, consumers decide unilaterally how much information to provide. In this context the monopolist never chooses to subsidize consumers, and we show in the next section that 
subsidization will only arise under competition. ${ }^{9}$

\section{Competing with privacy}

We next evaluate the case of duopoly. A straightforward implication of our model is that firms supplying homogeneous services will benefit from differentiated disclosure levels. Inspection of $u_{i, j}$ in (1) reveals that if two firms set the same disclosure level, they become perfect substitutes for consumers, so price competition then drives their profits down to zero. Thus, we let $j \in\{l, h\}$ and assume without loss of generality that $d_{l} \leq d_{h}$. Firm $l$ discloses less consumer information than firm $h$ (when the inequality is strict so that firms are differentiated), and as a consequence its product is perceived as being of higher quality than that of firm $h$.

Information provision. To solve for the equilibrium, note that consumer information provision in the fourth stage as characterized in (2) carries over to the case of duopoly for each firm.

Purchasing decisions. We examine the problem of consumer $i$ in the third stage when deciding whether to sign up with firm $l$ or with firm $h .{ }^{10}$ Consider first the case where the highdisclosure firm prices above the low-disclosure firm, $p_{h}>p_{l}$. In this case, all consumers derive higher utility from firm $l$, so firm $h$ obtains zero demand and profits. Below, we show that firm $h$ can obtain positive profits by undercutting the price of firm $l$. Therefore, $p_{h}>p_{l}$ will never arise in equilibrium.

Consider next the case where the high-disclosure firm sets a price lower than that of the lowdisclosure firm, $p_{h} \leq p_{l}$. When firms are differentiated, note that $\partial u_{i, l} / \partial v_{i}>\partial u_{i, h} / \partial v_{i}>0$ given equilibrium information provision $y_{j}$ in $(2)$, so that high-valuation consumers will sign up with firm $l$ and low-valuation consumers will sign up with firm $h$. We can identify the valuation of the pivot consumer $v_{p}$ who is strictly indifferent between signing up with firm $l$ and firm $h$ by equating $u_{p, l}=u_{p, h}$,

$$
v_{p}=\frac{4\left(p_{l}-p_{h}\right)}{\left(d_{h}-d_{l}\right)\left(2-d_{h}-d_{l}\right)}
$$

\footnotetext{
${ }^{9}$ It can be shown that subsidization also arises in our specification if information provision $y_{m}$ is chosen by the monopolist or assumed to be exogenous. Thus the absence of subsidization under monopoly is explained by the fact that consumers unilaterally decide their information provision. It is also worth noting that Akçura and Srinivasan (2005) consider a specification where disclosure revenues depend on consumer valuations. In our model, consumer valuations for the service and disclosure revenues are independent; higher consumer valuations do not translate into higher disclosure revenues. However, in some cases, both may be correlated. Wealthier consumers with a higher willingness to pay are also more valuable targets for advertisers. We note that if consumer valuations were positively correlated with disclosure revenues in our model, this would reduce the monopolist's incentives to cover the market, given that serving low valuation consumers becomes comparatively less profitable.

${ }^{10}$ As noted in Section 2 and proved below, our assumptions on the distribution of consumer valuations imply that the market is fully covered in equilibrium. We have also analyzed uncovered market configurations under duopoly, but unfortunately found them to be intractable. Nonetheless, we believe that the covered market configuration is empirically relevant given the high market penetration enjoyed by free or subsidized online services.
} 
When the market is covered, consumers with $v_{i} \in\left[V^{-}, v_{p}\right)$ sign up with firm $h$ and consumers $v_{i} \in\left[v_{p}, V^{+}\right]$sign up with firm $l$.

Duopoly pricing. Consider the pricing problem of both firms in the second stage. Profits in a covered market configuration given disclosure levels $d_{l}<d_{h}$ and prices $p_{h}<p_{l}$ are

$$
\begin{aligned}
\pi_{l}\left(p_{l}, p_{h}, d_{l}, d_{h}\right) & =\frac{V^{+}-v_{p}}{V^{+}-V^{-}}\left(p_{l}+d_{l} y_{l}\right) \\
\pi_{h}\left(p_{l}, p_{h}, d_{l}, d_{h}\right) & =\frac{v_{p}-V^{-}}{V^{+}-V^{-}}\left(p_{h}+d_{h} y_{h}\right) .
\end{aligned}
$$

Solving the corresponding system of price best-response functions we obtain a unique pair of equilibrium prices, $p_{l}\left(d_{l}, d_{h}\right)$ and $p_{h}\left(d_{l}, d_{h}\right)$.

Duopoly disclosures. Plugging equilibrium prices $p_{l}\left(d_{l}, d_{h}\right)$ and $p_{h}\left(d_{l}, d_{h}\right)$ from the previous step into firm profits $\pi_{l}$ and $\pi_{h}$ in (9) we obtain profits as a function of disclosure levels, $\pi_{l}\left(d_{l}, d_{h}\right)$ and $\pi_{h}\left(d_{l}, d_{h}\right)$. Solving the system of disclosure best-response functions we obtain the equilibrium disclosure levels, $d_{l}$ and $d_{h}$.

The following proposition presents the equilibrium.

Proposition 2. In the duopoly equilibrium, the market is covered and customers patronizing firm $j \in\{l, h\}$ provide information

$$
y_{j}=\frac{1-d_{j}}{2}
$$

Firms quote prices

$$
\begin{gathered}
p_{l}\left(d_{l}, d_{h}\right)=\left(d_{h}^{2}\left(2+V^{-}-2 V^{+}\right)-2 d_{h}\left(1+V^{-}-2 V^{+}\right)+d_{l}\left(d_{l}\left(4-V^{-}+2 V^{+}\right)-4+2 V^{-}-4 V^{+}\right)\right) / 12 \\
p_{h}\left(d_{l}, d_{h}\right)=\left(d_{l}^{2}\left(2-2 V^{-}+V^{+}\right)+d_{l}\left(-2+4 V^{-}-2 V^{+}\right)+d_{h}\left(d_{h}\left(4+2 V^{-}-V^{+}\right)-4-4 V^{-}+2 V^{+}\right)\right) / 12 .
\end{gathered}
$$

Consider the three parameter regions shown in Figure 2 below. In Region A, the equilibrium disclosures of both firms are in the interior:

$$
\begin{aligned}
& d_{l}=1+\frac{2}{3}\left(\frac{1}{V^{+}-V^{-}}-\sqrt{\frac{V^{+}-2 V^{-}+2}{\left(2+V^{-}-2 V^{+}\right)\left(V^{+}-V^{-}\right)^{2}}}\right) \\
& d_{h}=1-\frac{2}{3}\left(\frac{1}{V^{+}-V^{-}}-\sqrt{\frac{2 V^{+}-V^{-}-2}{\left(2 V^{-}-2-V^{+}\right)\left(V^{+}-V^{-}\right)^{2}}}\right) .
\end{aligned}
$$

In Region B, firm $l$ is at the corner where it chooses not to disclose consumer information:

$$
\begin{aligned}
d_{l} & =0 \\
d_{h} & =\frac{3}{2}-\frac{10-2 V^{-}+V^{+}}{2 \sqrt{\left(2-2 V^{-}+V^{+}\right)\left(10-2 V^{-}+V^{+}\right)}}
\end{aligned}
$$




\section{Equilibrium parameter regions}

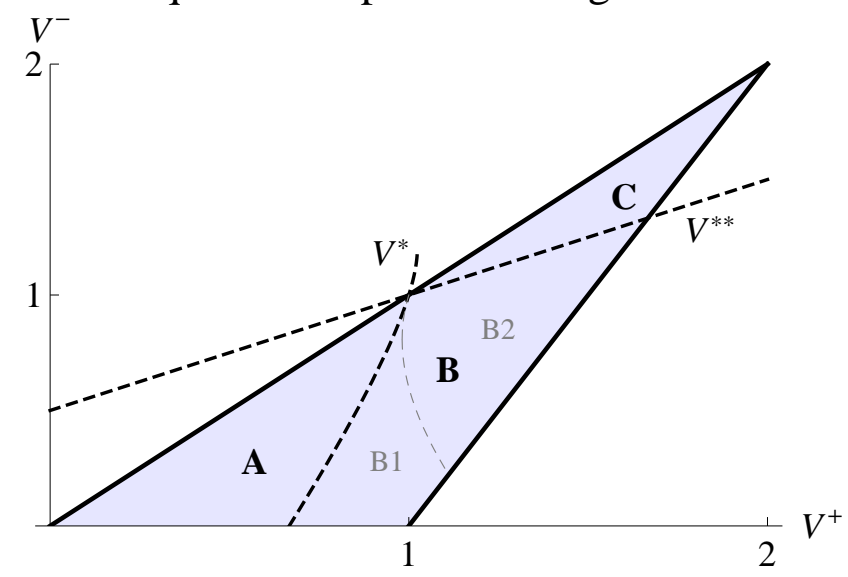

Plot parameter trajectories

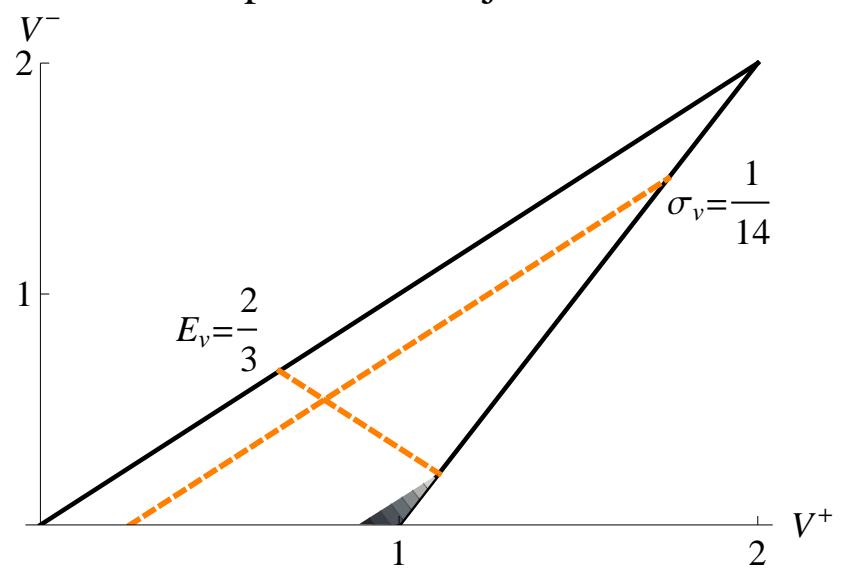

Figure 2: The left panel identifies parameter regions where the interior and corner solutions derived in Proposition 2 constitute an equilibrium. The mathematical derivations can be found in Appendix A. The right panel identifies the parameter trajectories used in the remaining figures of the paper. The shaded region in the right panel identifies the parameter region where uncovered market deviations pay off, as characterized in Appendix B.

Finally, in Region $C$ both firms are at the corner:

$$
\begin{aligned}
d_{l} & =0 \\
d_{h} & =0 .
\end{aligned}
$$

Proof. See Appendix A.

Firms competing with privacy benefit from differentiating in their levels of disclosure in order to cater to distinct consumer segments. The left panel in Figure 2 depicts three regions over the parameter space $\left(V^{-}, V^{+}\right)$which are denoted by A, B, and C. The equilibrium expressions for $d_{l}$ and $d_{h}$ differ across the three regions. Region A contains interior equilibria where both firms engage in disclosure $\left(0<d_{l}<d_{h}\right)$, Region $\mathrm{B}$ contains corner equilibria where only one of the firms engages in disclosure $\left(d_{l}=0<d_{h}\right)$, and Region $\mathrm{C}$ contains corner equilibria where neither firm engages in disclosure $\left(d_{l}=d_{h}=0\right)$. Region B is further subdivided into two subregions B1 and B2 where the profit ranking of both duopolists differs. Note that differentiation breaks down in Region $\mathrm{C}$ because engaging in disclosure is not profitable for firms when consumer valuations are high and mostly homogenous. This follows from the fact that firms engaging in disclosure need to subsidize consumers, but disclosure revenues are fixed and independent of consumer valuations. We further discuss this result and the profit ranking of firms in Section 5.1. In order to understand the shape of the three regions depicted in Figure 2, recall that we do not consider points above the $45^{\circ}$ line because $V^{-}<V^{+}$. Also, as we show in Appendix A, there are no equilibria with full market coverage when parameters $V^{-}$and $V^{+}$are to the right of the line with slope 2 that begins at $V^{+}=1$. The interior boundaries $V^{*}$ and $V^{* *}$ that separate the three regions originate from the 
disclosure best-responses of both firms. ${ }^{11}$

An important property of the duopoly solution is that firms (mostly) focus on a single revenue source. Firms choosing to engage in disclosure exploit disclosure revenues, and firms choosing not to engage in disclosure (or performing a low level of disclosure) exploit price revenues instead. Across most equilibria, firms engaging in disclosure subsidize consumers by quoting negative prices, and only firms that do not engage in disclosure quote positive prices. Differentiation, therefore, is reflected on both the level of disclosure firms engage in and also (as a consequence) on the revenue source they exploit. Moreover, disclosure levels are mutually reinforcing because they exhibit strategic complementarity; if one firm increases its level of disclosure the best-response of the other firm is to also increase its own level of disclosure (given that equilibrium best-responses satisfy $\partial \hat{d}_{l}^{b} / \partial d_{h}>0$ and $\left.\partial \hat{d}_{h}^{c} / \partial d_{l}>0\right)$. In the remaining of this section we review the properties of duopoly disclosure levels and prices and compare them with those of monopoly. We relegate our analysis of firm profits and information stocks to Section 5, where we also discuss the empirical implications of our results.

In order to review the properties of the duopoly solution, we proceed by separately reviewing the impact of changes in the spread and the mean of consumers' distribution of valuations. Consider the right panel in Figure 2. Note that the further away the parameter pair $\left(V^{-}, V^{+}\right)$is from the origin of coordinates, the larger the expected valuation of consumers for the services supplied by firms (valuation mean $E_{v}$ ). Likewise, the closer the parameter pair is to the $45^{\circ}$ line, the lower the heterogeneity in customer preferences (valuation spread $\sigma_{v}$ ). The dashed lines depict parameter trajectories where either the valuation mean or the valuation spread are constant. The upperslopped trajectory depicts pairs $\left(V^{-}, V^{+}\right)$such that $\sigma_{v}$ is constant but where $E_{v}$ increases (as $V^{+}$grows). The downward-slopped trajectory depicts pairs $\left(V^{-}, V^{+}\right)$such that $E_{v}$ is constant but where $\sigma_{v}$ increases (as $V^{+}$grows). We use these two parameter trajectories to generate the remaining figures of the paper.

The spread of the distribution of consumer valuations $\sigma_{v}$ determines the scope for differentiation in the marketplace. This in turn determines the intensity of competition, because it affects the ability of firms to compete when setting different levels of disclosure. ${ }^{12}$ Figure 3 depicts the impact of variations in the spread. When the spread is small, so that consumer valuations are almost homogeneous, both firms engage in a similar level of disclosure. This results in intense price competition and low profits, driving both firms to heavily subsidize consumers by quoting

\footnotetext{
${ }^{11}$ For completeness, we have also evaluated unilateral firm deviations to uncovered market configurations. The shaded region in the right panel in Figure 2 identifies parameter values where the solution derived in Proposition 2 does not constitute an equilibrium of the game in which firms may choose not to cover the market. The analysis of uncovered market deviations is included in Appendix B.

${ }^{12}$ Although our analysis is restricted to the case of duopoly, we expect the implications of consumer heterogeneity to apply more generally. Note that a lower valuation spread reduces the valuation differential between the consumers served by each firm. This drives firms to reduce their effective differentiation, or the difference in their levels of disclosure, in order to attract consumers. The same mechanism would be present with the entry of additional firms in the market.
} 

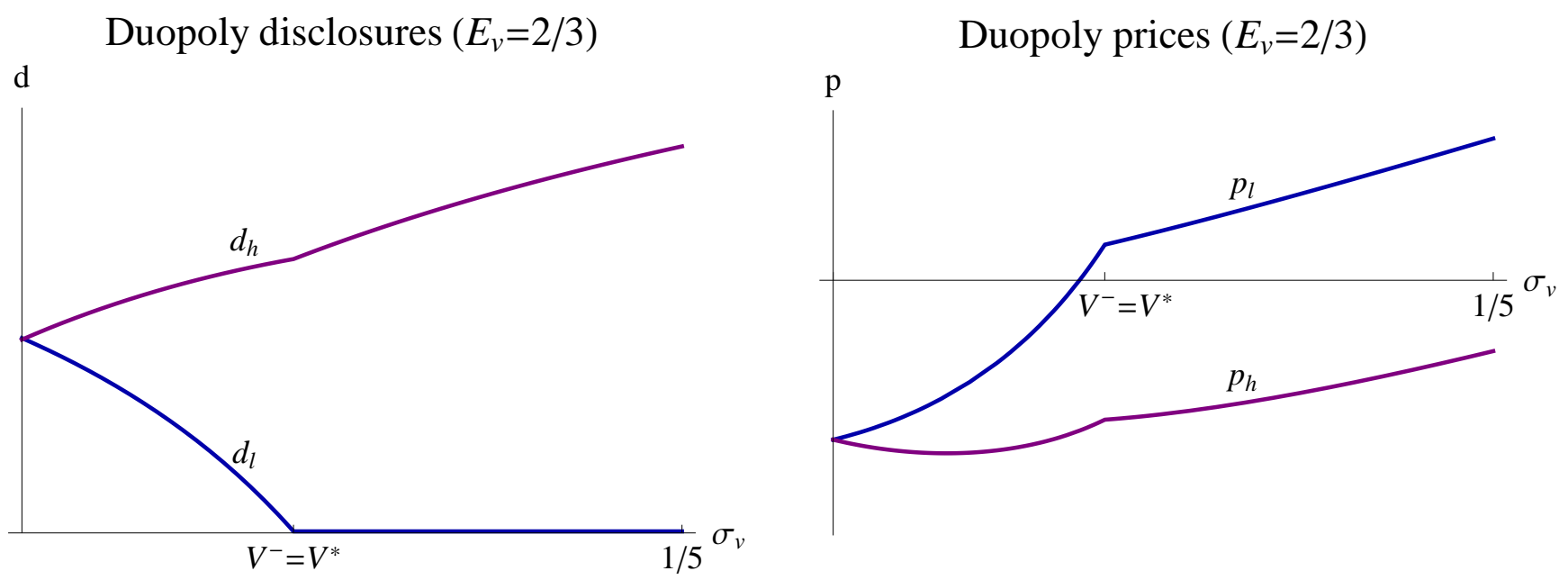

Figure 3: Duopoly disclosures (left) and prices (right) as a function of the consumer population's valuation spread.

negative prices. As the valuation spread converges to zero, $V^{+}-V^{-} \rightarrow 0$, the disclosure of both firms converges to the monopoly solution and firm profits converge to zero. When the spread increases so that consumers become more heterogeneous in their valuations, one firm chooses to increase its disclosure above that of the monopoly solution and the other firm reduces its disclosure below it, so that the effective differentiation of both firms increases. This softens price competition and allows firms to increase prices, thus increasing profits.

The impact of an increase in the valuation mean $E_{v}$ is depicted in Figure 4 . This increases the average willingness to pay of consumers and therefore increases potential price revenues for firms, which reduces the comparative attractiveness of disclosure revenues and drives them to reduce disclosure levels. When both firms are actively engaged in disclosure (Region A) they can do so increasing their differentiation, which allows them to increase their price and their profits. When consumer valuations are sufficiently high (Region B), the low-disclosure firm chooses not to engage in disclosure and focuses exclusively on price revenues. This is the only instance of positive prices that arises in equilibrium (with the exception of a small neighboring range of the parameter space). Effective differentiation is reduced as the high-disclosure firm further reduces its level of disclosure. When consumer valuations increase further (Region $\mathrm{C}$ ), neither firm engages in disclosure and competitive pressure drives prices and profits down to zero. We further discuss this outcome where differentiation breaks down in Section 5.1.

Having characterized the duopoly solution, our next proposition establishes the qualitative impact of competition in the marketplace.

Proposition 3. Comparison of the duopoly and monopoly solutions reveals that competition has two main effects on the marketplace: the introduction of a low-disclosure (high-quality) service when consumers exhibit low valuations $V^{-}<1$, given by $d_{l}<d_{h} \approx d_{m}$, and subsidization of the high-disclosure (low-quality) service, $p_{h} \leq 0<p_{m}$. 

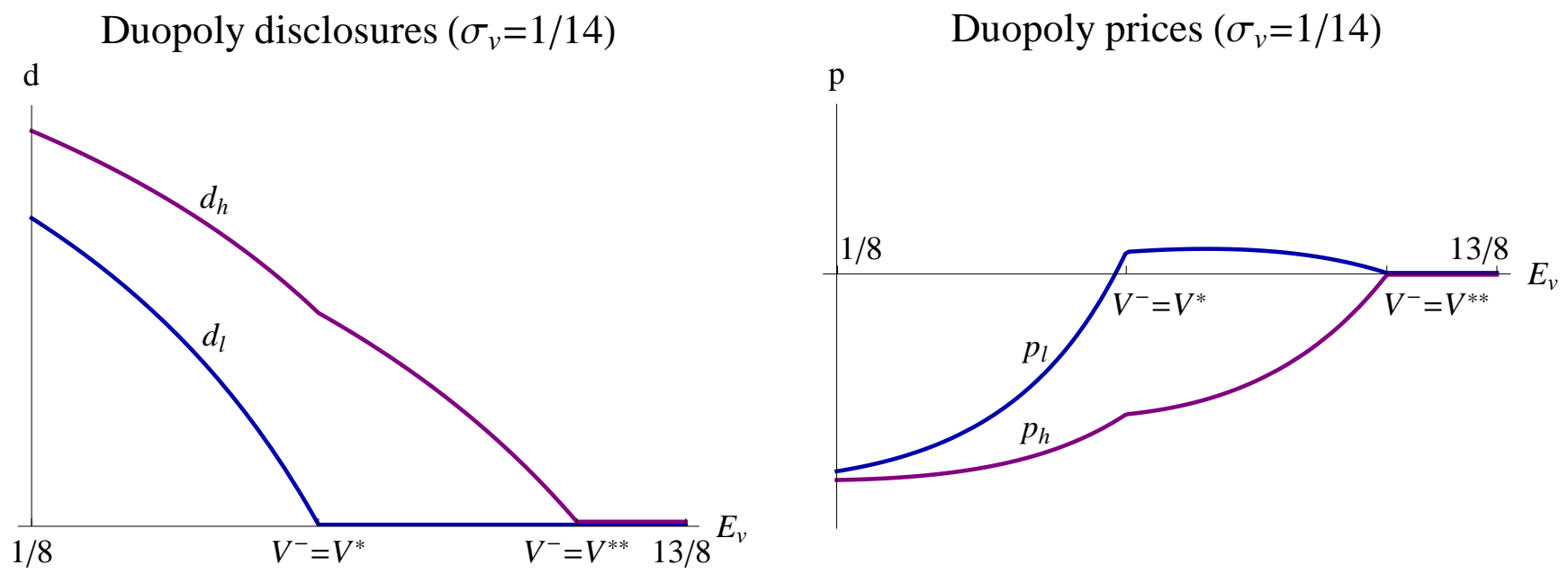

Figure 4: Duopoly disclosures (left) and prices (right) as a function of the consumer population's valuation mean.

The first part of the proposition follows from the fact that the monopolist chooses to engage in disclosure when low valuation consumers are present in the market, $V^{-}<1$. The high-disclosure duopolist sets a level of disclosure which is approximately equivalent to that of the monopolist though marginally higher. The low-disclosure duopolist, however, sets a disclosure level which is qualitatively different from that of the monopolist. This can be verified by inspection of monopoly disclosure $d_{m}$ in Figure 1 and duopoly disclosures $d_{l}$ and $d_{h}$ in Figures 3 and 4 (disclosures are plotted over the same range in the three figures). Note that when $V^{-}>1$, neither the monopolist nor the low-disclosure duopolist engage in disclosure. Therefore, whenever low valuation consumers are present in the market, our model predicts that low-disclosure services which are sustained exclusively by price revenues only arise under competition.

Regarding the second part of the proposition, note that the monopolist quotes a positive price but the duopolist supplying the high-disclosure service quotes a negative price to subsidize consumers (Regions A and B) or zero price when not engaging in disclosure (Region C). Clearly, the difference in pricing is due to the competitive pressure faced by the duopolist, as in both cases consumers exhibit positive willingness to pay for the service. It can be shown that the price differential under both regimes, $p_{m}-p_{h}$, decreases with the valuation spread $\sigma_{v}$ which determines the intensity of competition. Thus our model predicts that consumer subsidization in the presence of disclosure revenues is a direct consequence of competition.

It should be clear that both of the above effects of competition benefit consumers, allowing them to select into lower disclosure alternatives and subsidizing them under higher levels of disclosure. The first effect benefits high-valuation consumers the most, and the second effect benefits mainly low-valuation consumers. Both effects also contribute to explain the relative profitability obtained by each duopolist. In the next section we disentangle in more detail the impact of competition on firm profits and consumer surplus. 


\section{Discussion}

In this section we examine the managerial, policy, and empirical implications of our results. In order to proceed it is useful to formalize additional notation first. We will denote the market share

of firm $j$ by $s_{j}$. The market share of firm $j$ when serving consumers $v_{i} \in\left[v_{j}^{-}, v_{j}^{+}\right]$in a covered market can be written as

$$
s_{j}=\frac{v_{j}^{+}-v_{j}^{-}}{V^{+}-V^{-}} .
$$

We define the information stock of firm $j$, denoted by $Y_{j}$, as the total stock of consumer information accumulated by the firm in the marketplace. Given that the market is covered in equilibrium and information provision is homogenous across consumers signing up for each service, the information stock derived by firm $j$ is given by

$$
Y_{j}=s_{j} y_{j}
$$

The information disclosed by firm $j$, denoted by $Y_{j}^{d}$, is then given by $Y_{j}^{d}=d_{j} Y_{j}$.

We can write the surplus enjoyed in equilibrium by consumers signed up with firm $j$ as

$$
C S_{j}=\frac{1}{V^{+}-V^{-}} \int_{v_{j}^{-}}^{v_{j}^{+}} u_{i, j} \mathrm{~d} v_{i}
$$

We start by reviewing the managerial implications of our results.

\subsection{Managerial implications}

The profits of firms competing with privacy are asymmetric in our model. Profits vary with the valuations of the consumer population, and neither duopolist consistently outperforms the other one. Inspection of the duopoly solution yields the following result.

Proposition 4. Duopoly profits are increasing in the consumer valuation spread (decreasing in the intensity of competition) and non-monotonic with respect to the consumer valuation mean (willingness to pay). The high-disclosure firm derives higher profits and market share when the valuation mean is low $\left(\pi_{l}<\pi_{h}\right.$ and $s_{l}<s_{h}$ in Regions $A$ and B1), the low-disclosure firm derives higher profits and market share when the valuation mean is high $\left(\pi_{l}>\pi_{h}\right.$ and $s_{l}>s_{h}$ in Region B2), and both firms are engaged in Bertrand competition and derive zero profits when the valuation mean is very high $\left(\pi_{l}=\pi_{h}=0\right.$ in Region $\left.C\right)$.

The profits of both duopolists increase with the consumer valuation spread, given that a higher spread increases the scope for differentiation (see our discussion above in Section 4 as well as Figure 3). The mean valuation of the consumer population, which captures the willingness to pay, 

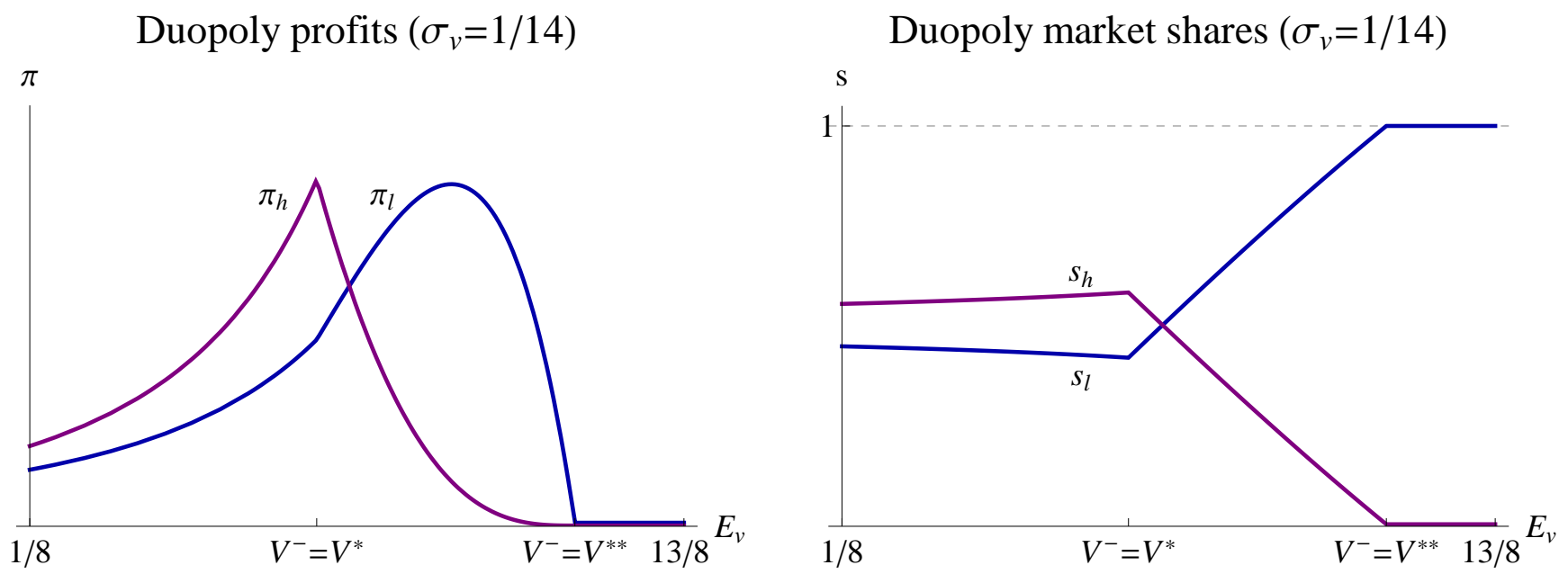

Figure 5: Duopoly profits (left) and market shares (right) as a function of the consumer population's valuation mean.

exhibits a more complex impact on profits and determines the profit ranking of both firms. When the mean valuation is low (Regions A and B1 in Figure 2), the high-disclosure firm derives higher profits in the marketplace. It achieves this by engaging in a high level of disclosure and heavily subsidizing consumers. Conversely, when the mean is high (Region B2), the low-disclosure firm outperforms the high-disclosure firm by quoting positive prices and not engaging in disclosure. When mean valuation is very high (Region $\mathrm{C}$ ), neither firm engages in disclosure and both derive zero profits. Figure 5 plots the profits and market shares of both firms to illustrate the argument.

The result is driven by the fact that disclosure prices are fixed (and exogenous) in our model, so the relative profitability of disclosure for firms depends on consumer valuations. When consumers exhibit low willingness to pay for the service, disclosure revenues are comparatively high, so the high-disclosure firm can offer subsidies to attract low-valuation consumers away from the competitor while remaining profitable. When consumers' willingness to pay for the service is high, however, disclosure revenues are low in comparison and attracting consumers to the highdisclosure service is less profitable. The low-disclosure firm becomes comparatively more attractive for consumers and can sustain positive prices. When the willingness to pay is very high, such that consumer valuations are high and mostly homogenous, disclosure revenues are insufficient for the high-disclosure firm to profitably attract consumers given that the subsidies required to do so would result in negative profits. Differentiation therefore cannot pay off, and both firms wind up supplying zero-disclosure services and face intense price competition. The result shows that an increase in consumers' willingness to pay, which would always benefit a monopolist, can render firms worse off under competition.

Another property of our model is that the profit ranking of firms corresponds with their market share ranking. As shown in Figure 5, the most profitable firm also commands a larger market share in the duopoly equilibrium. This implies that firms maximize profits at the extensive rather than 
the intensive margin, outperforming competitors by attracting a larger customer base rather than by extracting higher revenues from a smaller base. This holds for the firm exploiting disclosure revenues when consumer willingness to pay is low as well as for the firm exploiting price revenues when it is high. Although the result hinges on our assumption that consumer valuations are uniformly distributed, it suggests that market shares can be a good predictor of profitability even when firms exploit disclosure revenues (i.e., firms do not sacrifice profits for market share)

An immediate takeaway of our analysis is that lower disclosure (higher quality) does not imply higher profits in the marketplace. In fact, when the willingness to pay of the consumer population is low, the contrary is true. This outcome differs from that of a standard vertical differentiation model, where the highest quality firm is always the most profitable (and which corresponds to the low-disclosure firm in our model, which has the highest informational quality for consumers). Another point of divergence is that differentiation can break down in our model, with firms engaging in Bertrand competition when consumer valuations are very high. Both divergences are due to the presence of an additional revenue stream which is inversely related to quality, and which intensifies competition in our model by enabling firms to subsidize consumers. ${ }^{13}$

\subsection{Policy implications}

We next examine in more detail the implications of competition on the information stocks accumulated and disclosed by firms. This provides a useful metric of consumer privacy in the marketplace and determines (together with prices) the surplus derived by consumers. Inspection of $Y_{j}, Y_{j}^{d}$ and $C S_{j}$ provides the following result.

Proposition 5. Under duopoly, the stock of consumer information obtained by each firm is equivalent when they both engage in disclosure, and the low-disclosure firm's stock is larger when it chooses not to engage in disclosure $\left(Y_{h} \leq Y_{l}\right.$ with strict inequality if $\left.d_{l}=0\right)$. Total consumer information disclosed is decreasing in consumer valuation mean (willingness to pay) and non-monotonic with respect to consumer valuation spread (intensity of competition). Comparison of the duopoly and monopoly solutions reveals that competition generally lowers information disclosed and increases consumer surplus $\left(Y_{h}^{d}+Y_{l}^{d} \leq Y_{m}^{d}\right.$ except for a subset of Region B2, and $\left.C S_{h}+C S_{l}>C S_{m}\right)$.

To understand the result, consider first the determinants of the information stock accumulated by firms in the marketplace. The information stock obtained by each firm is a function of both

\footnotetext{
${ }^{13}$ See Wauthy (1996) for a detailed characterization of equilibrium market configurations and profits in the standard vertical differentiation model. We note that the Bertrand outcome in our model is similar to the preempted market configuration identified by Wauthy where the high-quality firm prices the low-quality firm out of the market. In our model, the high-quality firm cannot preempt the market by quoting a positive price because the low-quality firm can sustain negative prices with disclosure revenues. Competition is therefore more intense and the preempted market configuration arises only (under consumer indifference between both firms) when the high-quality firm lowers its price down to zero, effectively driving both firms to Bertrand competition. Also note that the market is never preempted by the low-quality firm in Wauthy's analysis nor in our model, despite the presence of disclosure revenues.
} 

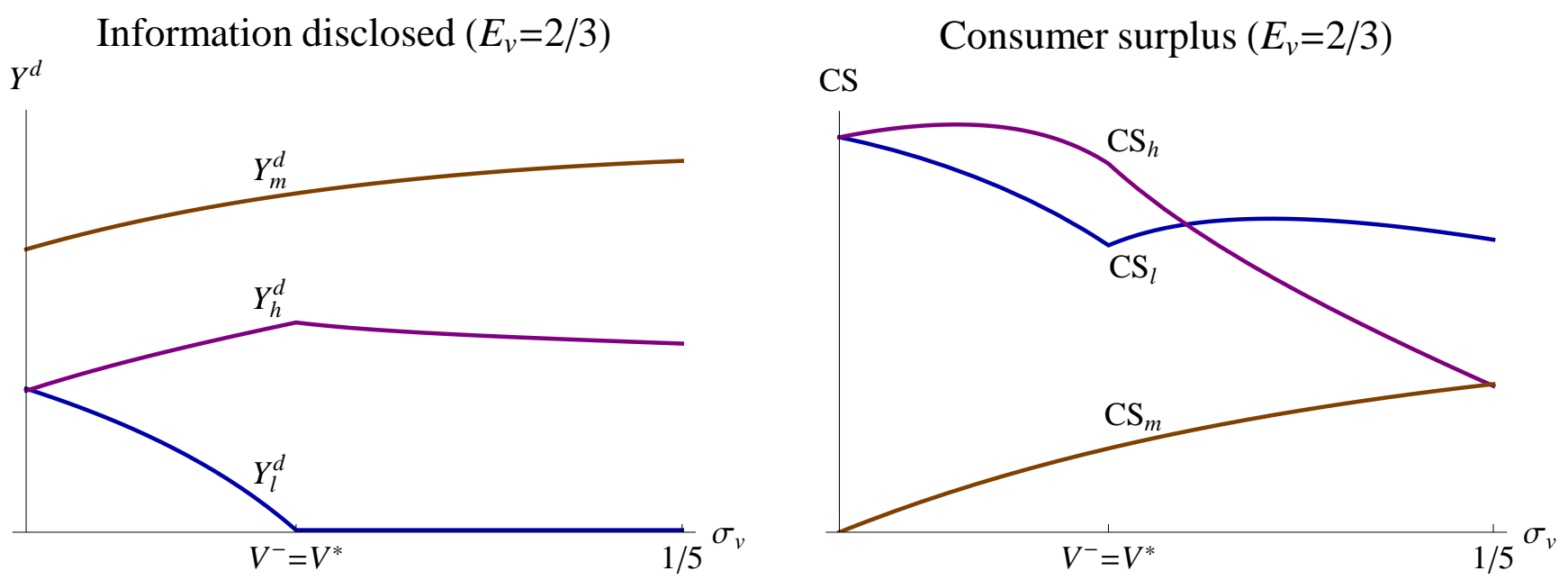

Figure 6: Information disclosed (left) and consumer surplus generated by each firm (right) as a function of the consumer population's valuation spread.

its user base and its level of disclosure - on how many consumers provide it with information and how much information each consumer provides. Under duopoly, when both firms engage in disclosure, they obtain the same information stock in equilibrium because asymmetries in their user bases and disclosure levels even out (Region A). When the low-disclosure firm does not engage in disclosure, it obtains a larger information stock than the competitor (Regions B and C, under consumer indifference in the latter).

The total information stock obtained by firms is generally larger under duopoly than under monopoly. When consumers with low valuations are present $\left(V^{-}<1\right)$ so that disclosure-intensive services are supplied under both market configurations, duopolists generally obtain a higher information stock. This follows from the fact that their average disclosure level is lower than that of the monopolist and consumer information provision is linear in disclosure. When no consumers with low valuations are present $\left(V^{-}>1\right)$ so that zero-disclosure services are supplied, the information stock accumulated by duopolists coincides with that of the monopolist. The exception to the above is the region neighboring $V^{-}=1$ where duopoly disclosures are marginally higher than that of the monopolist (the subset of Region B2 where $V^{-}>1$, given that $d_{m}=0<d_{h}$ ). Therefore, if the policy maker's goal were to maximize the information stock accumulated by firms in the marketplace, our model suggests that effective competition is the best way to achieve it.

Consider next the effective stock of information disclosed by firms, as depicted in Figure 6 . The total stock of information disclosed in the marketplace is generally lower under duopoly than under monopoly (with the exception of the subset of Region B2 noted above). Competition drives firms to accumulate a larger information stock and disclose a smaller part of it. Moreover, a high level of disclosure under competition need not result in a high volume of information disclosed, because consumers account for it when selecting which service to patronize. It can be shown that the effective stock of information disclosed by the high-disclosure firm in equilibrium $Y_{h}^{d}$ varies 
only marginally with its disclosure level $d_{h}$.

An important result of our model is that higher competition intensity need not improve consumer privacy in the marketplace. Or more precisely, a reduction in the spread of consumers' valuation distribution, which intensifies competition, can increase information disclosed $Y_{h}^{d}+Y_{l}^{d}$ rather than decrease it. The intuition for this result lies in the fact that firms can translate competitive pressure both to prices and to disclosure levels, so competition can discipline the former rather than the latter. Consider the impact of a reduction in the valuation spread that intensifies competition. When consumer valuations are low (Regions A and B1) firms tend to reduce prices and increase disclosure levels, driving up $Y_{h}^{d}+Y_{l}^{d}$. When consumer valuations are high (Region B2), firms tend to raise prices and reduce disclosure levels instead, driving down $Y_{h}^{d}+Y_{l}^{d}$. Intuitively, firms prefer to sacrifice the revenue source that is less profitable and can do so by compensating consumers through the other source (through lower prices, or through lower disclosure). Therefore, high volumes of disclosed information should be expected in a competitive marketplace when consumers' willingness to pay for services is low relative to the disclosure revenues available to firms. ${ }^{14}$

It is also interesting to evaluate the ranking of both duopolists in generating consumer surplus, which is also depicted in Figure 6. The high-disclosure duopolist generates higher consumer surplus in the market when it engages in high levels of disclosure (Region A and a neighboring subset of Region B). Recall that this duopolist sets a higher disclosure level than that of the monopolist in this range, $d_{h}>d_{m}$. The low-disclosure duopolist becomes the largest contributor to consumer surplus when it chooses not to engage in disclosure (most of Region B). The result underscores the fact that informed rational consumers can benefit both from services intensive in disclosure as well as from services that are not, and neither commands superior welfare properties in the marketplace.

\subsection{Empirical implications}

In this section we identify qualitative predictions that can be drawn from our results and tested with market data in future empirical research. We start by summarizing the properties of duopoly equilibria in our model. The following table identifies equilibrium predictions as a function of consumer valuations for the service.

\footnotetext{
${ }^{14}$ To evaluate the robustness of this result we have also analyzed the case where firms are horizontally differentiated, solving a Hotelling variant of our model where consumer utility is given by $u_{i, j}=v y_{i, j}\left(1-y_{i, j}-d_{j}\right)-t d_{i, j}-p_{j}$ (the analysis is available from the authors on request). In this model, consumers are homogeneous in their valuation $v$ but differ in their distance $d_{i, j}$ to firms, exhibiting an idiosyncratic preference for one of them. The intensity of competition is captured by transport cost parameter $t$. In a covered market equilibrium, it can be shown that firms set the monopoly disclosure level characterized in Proposition 1, so higher intensity of competition (lower transport cost $t$ ) does not improve consumer privacy. This confirms that our result is not an artifact of our focus on vertical differentiation, and suggests that consumer preferences play an important role in shaping the interplay of competition and privacy.
} 


\begin{tabular}{|c|c|c|c|c|}
\hline & \multicolumn{2}{|c|}{ Low spread $\sigma_{v}$} & \multicolumn{2}{|c|}{ High spread $\sigma_{v}$} \\
\hline High mean $E_{v}$ & (Region C) & $\begin{array}{c}p_{h}=p_{l}=0 \\
d_{l}=d_{h}=0 \\
\pi_{l}=\pi_{h}=0 \\
s_{l}+s_{h}=1 \\
Y_{l}=\frac{s_{l}}{2}, Y_{h}=\frac{s_{h}}{2}\end{array}$ & (Region B2) & $\begin{array}{c}p_{h}<0<p_{l} \\
d_{l}=0<d_{h} \\
\pi_{l}>\pi_{h} \\
s_{l}>s_{h} \\
Y_{l}>Y_{h}\end{array}$ \\
\hline Low mean $E_{v}$ & (Region A) & $\begin{array}{c}p_{h}<p_{l}<0 \\
0<d_{l}<d_{h} \\
\pi_{l}<\pi_{h} \\
s_{l}<s_{h} \\
Y_{l}=Y_{h}\end{array}$ & (Region B1) & $\begin{array}{c}p_{h}<0<p_{l} \\
d_{l}=0<d_{h} \\
\pi_{l}<\pi_{h} \\
s_{l}<s_{h} \\
Y_{l}>Y_{h}\end{array}$ \\
\hline
\end{tabular}

Firm profits are higher in the quadrants to the right where there is a high spread, as discussed in Section 5.1. To illustrate the properties of these quadrants it is useful to return to the Microsoft and Amazon examples we outlined in the introduction. Microsoft's Office 365 service matches the strategy of firm $l$ in the top-right quadrant, and Amazon's Special Offers program matches that of firm $h$ in the bottom-left quadrant. Microsoft competes with Google in the market for office software applications by committing to a no-disclosure policy and setting comparatively high prices for its Office 365 service. Amazon competes with Google in the market for retail search intermediation by engaging in a higher level of disclosure with third-party sellers and setting comparatively higher consumer subsidies with its Special Offers program. Google in turn competes by exploiting disclosure revenues in both markets. We expect average willingness to pay $E_{v}$ and consumer heterogeneity $\sigma_{v}$ to be higher in the market for office software than in that for retail search intermediation, among other factors because it is heavily participated by businesses in addition to consumers. Our analysis would then suggest that both Microsoft and Amazon are deploying successful business models to compete with Google in these markets.

Based on our preceding analysis and the equilibrium properties listed in the table, we next outline three main empirical predictions generated by our model.

Empirical prediction 1. (Business models) Firms enjoying significant market power exploit both price and disclosure revenues, and firms under competitive pressure exploit a single revenue source.

Proposition 1 shows that the monopolist exploits both disclosure and price revenues simultaneously, and Proposition 2 shows that firms under competitive pressure tend to exploit a single revenue source (see also Proposition 3 and our related discussion). This prediction implies that Microsoft and Amazon, which are under competitive pressure from Google in the markets identified in our examples, should exploit a single revenue source.

Empirical prediction 2. (Profitability) When the average willingness to pay is low (high) relative to potential disclosure revenues in a competitive marketplace, the high-disclosure (low-disclosure) firm realizes higher profits. 
Proposition 4 shows that the relative performance of firms competing with privacy depends on the valuation mean of the consumer population. When consumers' willingness to pay is low relative to the revenues firms can generate by disclosing their information, firms exploiting disclosure revenues derive higher profits. The contrary is true when the willingness to pay of consumers is relatively high. This prediction implies that Microsoft and Amazon should be more profitable than Google in the markets identified in our examples. We also note that market shares and profit rankings are positively correlated in our model, so we should expect Microsoft and Amazon to also derive larger market shares.

Empirical prediction 3. (Information) In a competitive marketplace, the low-disclosure firm only obtains a larger stock of consumer information than the high-disclosure firm when setting a no-disclosure policy.

Proposition 5 shows that the information stocks accumulated by both duopolists coincide when they both engage in a positive level of disclosure. When the low-disclosure firm chooses not to engage in disclosure, however, it obtains a larger information stock than the competitor. Therefore, Amazon and Google should accumulate an equivalent information stock from consumers in the market for retail search intermediation, given that they both engage in disclosure. In the market for office software applications, however, Microsoft should accumulate a larger information stock of documents than Google Docs because it provides a no-disclosure service while Google does not.

\section{Concluding remarks}

At the outset of this paper we set out to address some questions which can now be answered. First, how does privacy affect competition? Our analysis suggests that privacy can soften the intensity of competition when consumers (a) are heterogeneous so that firms can effectively differentiate in their privacy policies, and (b) their willingness to pay is not exceedingly high so that firms disclosing their information can operate profitably. Second, should firms exploit all available revenue sources, prices and disclosure, or focus on one? Firms under competitive pressure should focus on a single revenue source. Firms may exploit disclosure revenues and subsidize consumers in order to attract them to their service, or choose not to engage in disclosure and quote positive prices instead. Third, which strategy is more profitable and what does it depend on? When consumers' willingness to pay is low relative to the revenues generated by disclosing their information, firms focused on disclosure revenues will outperform their competitors. And conversely, firms focused on price revenues will perform better when the relative willingness to pay of consumers is high. In both cases, firms maximize profits at the extensive rather than the intensive margin, outperforming competitors by attracting a larger customer base to their service.

In concluding our analysis, it is important to stress that we provide a benchmark for informed and rational consumers. We expect increasing consumer awareness of disclosure practices and 
familiarity with its implications to reinforce its relevance. Recent surveys of consumer attitudes towards privacy underscore this trend. Alan Westin, a pioneering scholar in the field of privacy, noted in 2008 that "offering online users free email or free searches did not seem to a majority of our respondents to be a sufficient set of benefits or valued services to overcome the instinctive feeling of not wanting to be tracked and marketed to based on their online transactions and surfs." 15 We also expect transparency to play an important role in informing consumer decisions and delivering a competitive supply of services. Initiatives to make disclosure practices salient and understandable for consumers are clearly desirable from a policy perspective. But our results recommend caution on restricting disclosure practices. We have shown that high-disclosure services play an important role in a competitive marketplace and informed consumers adjust their choices accordingly.

Finally, our framework also provides a context to understand innovation in the provision of information-intensive services. Social networking, for instance, can be understood as a service innovation that generates utility for users willing to post information that would otherwise remain private. In the mobile app ecosystem, new services are flourishing that help consumers store and process snippets of their personal information. Firms supplying these innovative services are accumulating consumer information, and such information stocks generate new disclosure opportunities. Consumer data brokers are aggregating information from increasingly diverse sources, enabling these services to monetize consumer information snippets by contributing to broader profiling. And new instances of such services will continue to emerge with future advances in information technologies. These underlying technology drivers suggest that consumer privacy will continue to shape competition for the foreseeable future.

\footnotetext{
${ }^{15}$ See Alan Westin's report 'How online users feel about behavioral marketing and how adoption of privacy and security policies could affect their feelings,' Privacy Consulting Group, March 2008.
} 


\section{Appendix A}

Proof of Proposition 2. We solve the game by backwards induction. As discussed in Section 4, the equilibrium information provision of consumers patronizing firm $j \in\{l, h\}$ in the fourth stage is given by $y_{j}=\frac{1-d_{j}}{2}$. To characterize consumer purchases in the third stage when $d_{l}<d_{h}$ and $p_{h}<p_{l}$, let $v_{p}\left(p_{l}, p_{h}, d_{l}, d_{h}\right)=\frac{4\left(p_{l}-p_{h}\right)}{\left(d_{h}-d_{l}\right)\left(2-d_{h}-d_{l}\right)}$ be the valuation of the consumer indifferent between purchasing from firm $l$ and firm $h$. Consumers with $v_{i} \in\left[V^{-}, v_{f}\right)$ stay out of the market, where $v_{f}=\frac{4 p_{h}}{\left(1-d_{h}\right)^{2}}$ is the valuation of the consumer indifferent between signing up and staying out of the market. Consumers with $v_{i} \in\left[v_{f}, v_{p}\right)$ sign up with firm $h$ and consumers with $v_{i} \in\left[v_{p}, V^{+}\right]$ sign up with firm $l$. Note that a covered market configuration requires $v_{f} \leq V^{-}$. We proceed to characterize equilibrium prices and disclosures assuming the market is covered and later verify that the solution indeed satisfies $v_{f} \leq V^{-}$.

To solve for the equilibrium choices of both firms, note that profit functions in a covered market are as follows: $\pi_{l}\left(p_{l}, p_{h}, d_{l}, d_{h}\right)=\frac{V^{+}-v_{p}}{V^{+}-V^{-}}\left(p_{l}+d_{l} y_{l}\right)$ and $\pi_{h}\left(p_{l}, p_{h}, d_{l}, d_{h}\right)=\frac{v_{p}-V^{-}}{V^{+}-V^{-}}\left(p_{h}+d_{h} y_{h}\right)$. To solve for prices in the second stage, we can easily derive the price best-response functions and solve for the equilibrium to obtain:

$$
\begin{aligned}
& p_{l}\left(d_{l}, d_{h}\right)=\left(d_{h}^{2}\left(2+V^{-}-2 V^{+}\right)-2 d_{h}\left(1+V^{-}-2 V^{+}\right)+d_{l}\left(d_{l}\left(4-V^{-}+2 V^{+}\right)-4+2 V^{-}-4 V^{+}\right)\right) / 12 \\
& p_{h}\left(d_{l}, d_{h}\right)=\left(d_{l}^{2}\left(2-2 V^{-}+V^{+}\right)+d_{l}\left(-2+4 V^{-}-2 V^{+}\right)+d_{h}\left(d_{h}\left(4+2 V^{-}-V^{+}\right)-4-4 V^{-}+2 V^{+}\right)\right) / 12 .
\end{aligned}
$$

It is immediate to verify that the second-order conditions are satisfied at these prices.

In the first stage, firms choose disclosure levels $d_{l}$ and $d_{h}$. We substitute $p_{l}\left(d_{l}, d_{h}\right)$ and $p_{h}\left(d_{l}, d_{h}\right)$ in $\pi_{l}\left(p_{l}, p_{h}, d_{l}, d_{h}\right)$ and $\pi_{h}\left(p_{l}, p_{h}, d_{l}, d_{h}\right)$ to obtain profits as functions of $d_{l}$ and $d_{h}$ alone. Solving $\partial \pi_{j}\left(d_{j}, d_{-j}\right) / \partial d_{j}=0$ for each firm identifies three candidate best-responses per firm. Denote the candidate best-responses of firm $j$ by $\hat{d}_{j}^{k}$ and let superscript $k \in\{a, b, c\}$ identify each of the three solutions, then

$$
\begin{aligned}
& \hat{d}_{l}^{a}=2-d_{h}-\frac{2}{V^{-}-2 V^{+}+2} \\
& \hat{d}_{l}^{b}=\frac{3-d_{h}}{2}+\frac{\sqrt{\left(2 V^{+}-V^{-}-2\right)\left(1-d_{h}\right)\left(2\left(\left(1-V^{+}\right) d_{h}+V^{+}-5\right)-V^{-}\left(1-d_{h}\right)\right)}}{4 V^{+}-2 V^{-}-4} \\
& \hat{d}_{l}^{c}=\frac{3-d_{h}}{2}-\frac{\sqrt{\left(2 V^{+}-V^{-}-2\right)\left(1-d_{h}\right)\left(2\left(\left(1-V^{+}\right) d_{h}+V^{+}-5\right)-V^{-}\left(1-d_{h}\right)\right)}}{4 V^{+}-2 V^{-}-4} \\
& \hat{d}_{h}^{a}=2-d_{l}-\frac{2}{V^{+}-2 V^{-}+2} \\
& \hat{d}_{h}^{b}=\frac{3-d_{l}}{2}+\frac{\sqrt{\left(V^{+}-2 V^{-}+2\right)\left(1-d_{l}\right)\left(V^{+}-2 V^{-}\left(1-d_{l}\right)-\left(2+V^{+}\right) d_{l}+10\right)}}{2 V^{+}-4 V^{-}+4} \\
& \hat{d}_{h}^{c}=\frac{3-d_{l}}{2}-\frac{\sqrt{\left(V^{+}-2 V^{-}+2\right)\left(1-d_{l}\right)\left(V^{+}-2 v\left(1-d_{l}\right)-\left(2+V^{+}\right) d_{l}+10\right)}}{2} .
\end{aligned}
$$

To identify valid best-responses, note that $\hat{d}_{l}^{k}$ is only a best-response for firm $l$ when it satisfies 
the second-order condition $\partial^{2} \pi_{l}\left(\hat{d}_{l}^{k}, d_{h}\right) / \partial d_{l}^{2}<0$, given the disclosure ordering $\hat{d}_{l}^{k} \leq d_{h}$ taking $d_{h}$ as exogenous. This identifies a parameter space over $V^{-}, V^{+}$, and $d_{h}$ for each valid best-response of firm $l$, and allows us to discard $\hat{d}_{l}^{c}$ which is never a valid best-response. The same process can be repeated to identify the valid best-responses of firm $h$, where the disclosure ordering is given by $d_{l} \leq \hat{d}_{h}^{k}$ taking $d_{l}$ as exogenous. This allows us to discard $\hat{d}_{h}^{a}$. The valid best-responses of both firms are given by

$\hat{d}_{l}^{a}$ is a valid best-response when $V^{-}<2 V^{+}-2$ and $\frac{1+V^{-}-2 V^{+}}{2+V^{-}-2 V^{+}}<d_{h}$

$\hat{d}_{l}^{b}$ is a valid best-response when $V^{-}>2 V^{+}-2$ and $\left(\frac{1+V^{-}-2 V^{+}}{2+V^{-}-2 V^{+}}<d_{h}<1\right.$ or $\left.d_{h}>\frac{10+V^{-}-2 V^{+}}{2+V^{-}-2 V^{+}}\right)$

$\hat{d}_{h}^{b}$ is a valid best-response when $d_{l}<1$

$\hat{d}_{h}^{c}$ is a valid best-response when $d_{l}<\frac{1-2 V^{-}+V^{+}}{2-2 V^{-}+V^{+}}$.

We next identify candidate equilibria by solving for $d_{l}$ and $d_{h}$ based on each combination of valid best-responses for firm $l$ and firm $h$, and evaluate whether the solution is contained in the parameter space where both best-responses hold. It can be readily verified that the single candidate equilibrium in the game is given by $\hat{d}_{l}^{b}$ and $\hat{d}_{h}^{c}$. Also note that $\partial \hat{d}_{l}^{b} / \partial d_{h}>0$ and $\partial \hat{d}_{h}^{c} / \partial d_{l}>0$, so firm disclosures are strategic complements. Firm disclosures in the candidate equilibrium are characterized by

$$
\begin{aligned}
& d_{l}^{b c}=1+\frac{2}{3}\left(\frac{1}{V^{+}-V^{-}}-\sqrt{\frac{V^{+}-2 V^{-}+2}{\left(2+V^{-}-2 V^{+}\right)\left(V^{+}-V^{-}\right)^{2}}}\right) \\
& d_{h}^{b c}=1-\frac{2}{3}\left(\frac{1}{V^{+}-V^{-}}-\sqrt{\frac{2 V^{+}-V^{-}-2}{\left(2 V^{-}-2-V^{+}\right)\left(V^{+}-V^{-}\right)^{2}}}\right)
\end{aligned}
$$

within the parameter space

$$
V^{-}>2 V^{+}-2
$$

For the candidate equilibrium to hold, firm disclosures must be contained within the valid disclosure range, $d_{j} \in[0,1]$. Corner solutions need to be considered when valid best-responses fall outside the valid disclosure range. Inspection of $d_{l}^{b c}$ and $d_{h}^{b c}$ reveals that firm disclosures in the candidate equilibrium can adopt negative values. The parameter space for interior and corner solutions can be identified by determining the range where firm l's best-response binds $d_{l}^{b c} \leq 0$ and evaluating whether the best-response of firm $h$ given by $\hat{d}_{h}^{c}\left(d_{l}=0\right)$ also binds or not. This identifies the following regions within the solution space,

$$
\begin{gathered}
0<d_{l}^{b c}<d_{h}^{b c}<1 \text { when } V^{-}>V^{*} \text { and } V^{+}<1 \\
d_{l}^{b c}=0<d_{h}^{b c}<1 \text { when }\left(V^{-} \leq V^{*} \text { and } V^{+}<1\right) \text { or }\left(V^{-}<V^{* *} \text { and } V^{+} \geq 1\right) \\
d_{l}^{b c}=d_{h}^{b c}=0 \text { when } V^{-} \geq V^{* *} \text { and } V^{+}>1
\end{gathered}
$$


where

$$
\begin{aligned}
V^{*} & =\frac{1}{6}\left(9 V^{+}-2-\sqrt{52-60 V^{+}+9\left(V^{+}\right)^{2}}\right) \\
V^{* *} & =\frac{1+V^{+}}{2} .
\end{aligned}
$$

The interior and corner solutions identified above must yield a covered market in order to constitute an equilibrium. Inspection of the indifferent consumer $v_{f}\left(p_{h}, d_{h}\right)$ across the interior and corner solutions reveals that $v_{f} \leq V^{-}$is always the case, so the market is effectively covered.

\section{Appendix B}

This appendix examines whether the solution characterized in Proposition 2 constitutes an equilibrium of the game in which firms may choose not to cover the market. We proceed by evaluating unilateral deviations to uncovered market configurations by each firm, and show that such deviations only pay off for firm $h$ in a small region of the solution space. This region is depicted in the right panel of Figure 2.

A unilateral deviation by firm $j$ to an uncovered market configuration consists of a disclosureprice pair $d_{j}^{u}$ and $p_{j}^{u}$ which satisfies $v_{f}>V^{-}$(ensures that low-valuation consumers prefer not to purchase) taking the other firm's strategy as fixed and given by $d_{-j}$ and $p_{-j}$ characterized in Proposition 2. Recall that consumers with higher valuation $v_{i} \geq v_{f}$ always prefer to participate in the market given that $\partial u_{i, j} / \partial v_{i}>0$, so an uncovered market configuration implies that low valuation consumers choose not to participate. We consider unilateral deviations by firms in the first and second stages of the game that satisfy $d_{l} \leq d_{h}$ and $p_{l} \geq p_{h}$, and evaluate their impact on consumer demand and information provision $y_{j}^{u}$ in the third and fourth stages.

We need only consider deviations by firm $h$. Note that deviations by firm $l$ cannot yield an uncovered market given that firm $h$ 's equilibrium strategy in Proposition 2 ensures that $v_{f} \leq V^{-}$, so no unilateral deviation by firm $l$ can yield an uncovered market. A unilateral deviation by firm $h$ that yields an uncovered market can result in three different market configurations. If $V^{-}<v_{f}<v_{p}<V^{+}$after the deviation, both firms continue to derive positive demand. If

$V^{-}<v_{f}<V^{+} \leq v_{p}$, firm $h$ takes over the market and serves all participating consumers. If $v_{f} \geq v_{p}$, firm $h$ derives no demand after the deviation. We can dismiss the last case because such a deviation will never payoff for firm $h$.

Consider first the case of deviations where both firms derive positive demand. The deviation profits of firm $h$, to be denoted by $\pi_{h}^{u}$, can then be written as

$$
\pi_{h}^{u}\left(p_{l}, p_{h}^{u}, d_{l}, d_{h}^{u}\right)=\frac{v_{p}-v_{f}}{V^{+}-V^{-}}\left(p_{h}^{u}+d_{h}^{u} y_{h}^{u}\right)
$$

where the pivot consumer $v_{p}$ is given by (8), the indifferent consumer $v_{f}$ by (3), and consumer information provision for the deviating firm $y_{h}^{u}$ by (2), accounting for firm $h$ 's deviation disclosure 
$d_{h}^{u}$ and price $p_{h}^{u}$. In order to identify the most profitable deviation we next solve for the optimal deviation price of firm $h$,

$$
p_{h}^{u}=\frac{\left(1-d_{h}^{u}\right)\left(2\left(1-d_{h}\right) p_{l}-d_{h}\left(1-d_{l}\right)^{2}\right)}{4\left(1-d_{l}\right)^{2}} .
$$

We next argue that it is optimal for firm $h$ to take over the market and serve all participating consumers when deviating to an uncovered market configuration. Plugging $d_{l}$ and $p_{l}$ from Proposition 2 and optimal deviation price $p_{h}^{u}$ in (10) into the pivot consumer $v_{p}$ in (8) as well as the indifferent consumer $v_{f}$ in (3), it can be shown that $v_{p}\left(p_{l}, p_{h}^{u}, d_{l}, d_{h}^{u}\right)-v_{f}\left(p_{h}^{u}, d_{h}^{u}\right)>V^{+}-V^{-}$for all $d_{h}^{u} \in\left[d_{l}, 1\right]$ across the solution space characterized in Proposition 2. This implies that it is always optimal for firm $h$ to take over the market when deviating, because the optimal price in an uncovered market configuration where $v_{f}>V^{-}$ensures that $v_{p}>V^{+}$so that all participating consumers purchase from firm $h$.

The deviation profits of firm $h$ in an uncovered takeover configuration (where it takes over the market) are given by

$$
\pi_{h}^{u, t}\left(p_{l}, p_{h}^{u}, d_{l}, d_{h}^{u}\right)=\frac{V^{+}-v_{f}}{V^{+}-V^{-}}\left(p_{h}^{u}+d_{h}^{u} y_{h}^{u}\right) .
$$

The optimal deviation price of firm $h$ is then the highest price that ensures that all participating consumers sign up to its service. The pivot consumer must then be given by $v_{p}=V^{+}$. Denote this deviation price by $p_{h}^{u, t}$. Equating $u_{i, l}\left(p_{l}, d_{l}\right)=u_{i, h}\left(p_{h}^{u, t}, d_{h}^{u}\right)$ for consumer $v_{i}=V^{+}$and solving for $p_{h}^{u, t}$ yields

$$
p_{h}^{u, t}=\frac{1}{4}\left(4 p_{l}-V^{+}\left(d_{h}^{u}-d_{l}\right)\left(2-d_{h}^{u}-d_{l}\right) .\right.
$$

Closed-form solutions for optimal deviation disclosure $d_{h}^{u}$ cannot be derived, unfortunately. We proceed by determining the disclosure range for $d_{h}^{u}$ to yield an uncovered market given optimal deviation price $p_{h}^{u, t}$. Denote the upper boundary of this disclosure range by $\bar{d}_{h}^{u}$. Solving for $v_{f}\left(p_{h}^{u, t}, d_{h}^{u}\right)=V^{-}$obtains two candidate solutions. It can be shown by plugging $d_{l}$ and $p_{l}$ from Proposition 2 (for the interior and corner cases) into both candidate solutions that only the following one is well defined within the feasible disclosure range $d_{h} \in[0,1]$,

$$
\bar{d}_{h}^{u}=\frac{V^{+}-V^{-}+\sqrt{\left(V^{+}-V^{-}\right)\left(V^{+}\left(1-d_{l}\right)^{2}-4 p_{l}\right)}}{V^{+}-V^{-}} .
$$

We have established that a unilateral deviation by firm $h$ to an uncovered market configuration can only be profitable in the disclosure range $d_{h}^{u}<\bar{d}_{h}^{u}$ and entails firm $h$ setting price $p_{h}^{u, t}$ to take over the market. Outside this disclosure range, the optimal pricing strategy of firm $h$ implies covering the market, and therefore cannot yield higher profits than those derived in the solution characterized in Proposition 2. Given that a closed-form solution is not available, we use numerical analysis to identify profitable deviations. We identify parameter pairs $\left(V^{-}, V^{+}\right)$within the solution space of Proposition 2 where deviations by firm $h$ to price $p_{h}^{u, t}$ in (11) and disclosure in the range 
$d_{h}^{u} \in\left[d_{l}, \bar{d}_{h}^{u}\right)$ where $\bar{d}_{h}^{u}$ is given by (12) yield a higher profit than that derived in the covered market

equilibrium, $\pi_{h}^{u, t}>\pi_{h}$. The region where uncovered market deviations pay off for firm $h$ is depicted in the right panel of Figure 2, and the code used to perform the numerical analysis is available from the authors on request.

\section{References}

[1] Acquisti, Alessandro and Hal R. Varian (2005), 'Conditioning Prices on Purchase History,' Marketing Science 24:3 367-381

[2] Akçura, M. Tolga and Kannan Srinivasan (2005), 'Research Note: Customer Intimacy and Cross-Selling Strategy,' Management Science 51:6 1007-1012

[3] Armstrong, Mark (2006), 'Competition in two-sided markets,' RAND Journal of Economics $37: 3668-691$

[4] Baccara, Mariagiovanna (2007), 'Outsourcing, information leakage, and consulting firms,' RAND Journal of Economics 38:1 269-289

[5] Caillaud, Bernard and Bruno Jullien (2003), 'Chicken \& Egg: Competition among Intermediation Service Providers,' RAND Journal of Economics 34:2 309-328

[6] Calzolari, Giacomo and Alessandro Pavan (2006), 'On the optimality of privacy in sequential contracting,' Journal of Economic Theory 130 168-204

[7] Casadesus-Masanell, Ramon and Feng Zhu (2010), 'Strategies to Fight Ad-sponsored Rivals,' Management Science 56:9 1484-1499

[8] Chellappa, Ramnath K. and Raymond G. Sin (2005), 'Personalization versus Privacy: An Empirical Examination of the Online Consumer's Dilemma,' Information Technology and Management 6 181-202

[9] Conitzer, Vincent, Curtis R. Taylor, and Liad Wagman (2012), 'Hide and Seek: Costly Consumer Privacy in a Market with Repeat Purchases,' Marketing Science (forthcoming)

[10] Goldfarb, Avi and Catherine E. Tucker (2010), 'Privacy Regulation and Online Advertising,' Management Science 57:1 57-71

[11] Hermalin, Benjamin E. and Michael L. Katz (2006), 'Privacy, property rights and efficiency: The economics of privacy as secrecy,' Quantitative Marketing and Economics 4 209-239

[12] Hui, Kai-Lung and I. P. L. Png (2006), 'The Economics of Privacy,' in Economics and Information Systems I 471-493 
[13] Noam, Eli M. (1995a), 'Privacy in Telecommunications: Markets, Rights, and Regulations. Part I,' New Telecom Quarterly 3:2 52-59

[14] Noam, Eli M. (1995b), 'Privacy in Telecommunications: Markets, Rights, and Regulations. Part III,' New Telecom Quarterly 3:4 51-60

[15] Posner, Richard A. (1981), 'The economics of privacy,' American Economic Review 71:2 405409

[16] Preibusch, Sören and Joseph Bonneau (2013), 'The Privacy Landscape: Product Differentiation on Data Collection,' in Economics of Information Security and Privacy III 263-283

[17] Rochet, Jean-Charles and Jean Tirole (2003), 'Platform competition in two-sided markets', Journal of the European Economic Association 1:4 990-1029

[18] Sandholm, William H. (2005), 'Negative Externalities and Evolutionary Implementation,' Review of Economic Studies 72 885-915

[19] Spulber, Daniel F. (2009), 'The map of commerce: Internet search, competition, and the circular flow of information,' Journal of Competition Law \& Economics 5:4 633-682

[20] Stigler, George J. (1980), 'An introduction to privacy in economics and politics,' The Journal of Legal Studies 9:4 623-644

[21] Taylor, Curtis R. (2004), 'Consumer privacy and the market for customer information,' RAND Journal of Economics 35:4 631-650

[22] Tsai, Janice Y., Serge Egelman, Lorrie Cranor, and Alessandro Acquisti (2011), 'The Effect of Online Privacy Information on Purchasing Behavior: An Experimental Study,' Information Systems Research 22:2 254-268

[23] Tucker, Catherine (2011), 'Social Networks, Personalized Advertising, and Privacy Controls,' MIT Sloan Research Paper 4851-10

[24] Van Zandt, Timothy (2004), 'Information Overload in a Network of Targeted Communication,' RAND Journal of Economics 35:3 542-560

[25] Villas-Boas, J. Miguel (2004), 'Price cycles in markets with customer recognition,' RAND Journal of Economics 35:3 486-501

[26] Wauthy, Xavier (1996), 'Quality Choice in Models of Vertical Differentiation,' Journal of Industrial Economics 44:3 345-353 